Please do not remove this page

RMIT

UNIVERSITY

\title{
Effect of environmental weathering on flexural creep behavior of long fiber-reinforced thermoplastic composites
}

Chevali, Venkata; Dean, Derrick; Janowski, Gregg

https://researchrepository.rmit.edu.au/esploro/outputs/9921859254301341/filesAndLinks?institution=61RMIT_INST\&index=null

Chevali, V., Dean, D., \& Janowski, G. (2010). Effect of environmental weathering on flexural creep behavior of long fiber-reinforced thermoplastic composites. Polymer Degradation and Stability, 95(12), 2628-2640. https://doi.org/10.1016/j.polymdegradstab.2010.07.019

Document Version: Accepted Manuscript

Published Version: https://doi.org/10.1016/j.polymdegradstab.2010.07.019

Repository homepage: https://researchrepository.rmit.edu.au

(C) 2010 Elsevier Ltd. All rights reserved.

Downloaded On 2023/04/26 19:36:12 +1000 
Thank you for downloading this document from the RMIT Research Repository.

The RMIT Research Repository is an open access database showcasing the research outputs of RMIT University researchers.

RMIT Research Repository: http://researchbank.rmit.edu.au/

\section{Citation:}

Chevali, V, Dean, D and Janowski, G 2010, 'Effect of environmental weathering on flexural creep behavior of long fiber-reinforced thermoplastic composites', Polymer Degradation and Stability, vol. 95, no. 12, pp. 2628-2640.

See this record in the RMIT Research Repository at:

http://researchbank.rmit.edu.au/view/rmit:18658

Version: Accepted Manuscript

Copyright Statement: (c) 2010 Elsevier Ltd. All rights reserved.

Link to Published Version:

http://dx.doi.org/10.1016/j.polymdegradstab.2010.07.019 


\section{Accepted Manuscript}

Title: Effect of environmental weathering on flexural creep behavior of long fiberreinforced thermoplastic composites

Authors: Venkata S. Chevali, Derrick R. Dean, Gregg M. Janowski

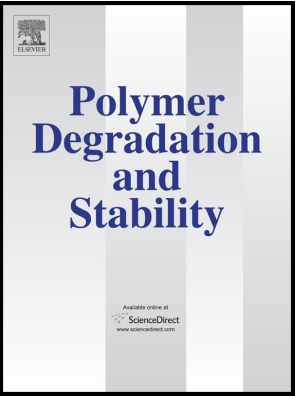

PII:

S0141-3910(10)00313-7

DOI:

10.1016/j.polymdegradstab.2010.07.019

Reference: $\quad$ PDST 6140

To appear in: Polymer Degradation and Stability

Received Date: 7 May 2010

Revised Date: 12 July 2010

Accepted Date: 26 July 2010

Please cite this article as: Chevali VS, Dean DR, Janowski GM. Effect of environmental weathering on flexural creep behavior of long fiber-reinforced thermoplastic composites, Polymer Degradation and Stability (2010), doi: 10.1016/j.polymdegradstab.2010.07.019

This is a PDF file of an unedited manuscript that has been accepted for publication. As a service to our customers we are providing this early version of the manuscript. The manuscript will undergo copyediting, typesetting, and review of the resulting proof before it is published in its final form. Please note that during the production process errors may be discovered which could affect the content, and all legal disclaimers that apply to the journal pertain. 


\section{EFFECT OF ENVIRONMENTAL WEATHERING ON FLEXURAL CREEP BEHAVIOR OF LONG FIBER-REINFORCED THERMOPLASTIC COMPOSITES}

by

Venkata S. Chevali*, Derrick R. Dean, and Gregg M. Janowski

${ }^{b}$ Department of Materials Science and Engineering

The University of Alabama at Birmingham $15303^{\text {rd }}$ Avenue South Birmingham AL 35205 USA

* Corresponding Author: venkata.chevali@ndsu.edu. Present address: Mechanical Engineering Dolve 111 NDSU Dept. 2490 PO Box 6050 Fargo ND 58108 USA. Ph: 701-231-5666 Fax: 701-231-8913 


\begin{abstract}
Flexural creep behavior of nylon 6/6 (NY66) - and polypropylene (PP) -based long fiber ( $l / d=2000$ - 10000) thermoplastic (LFT) composites was investigated as a function of ultraviolet irradiation and moisture absorption. Extrusion/compression-molded panels were prepared according to ASTM D-2990 and conditioned according to ASTM D-618. NY66 and PP LFTs were characterized using scanning electron microscopy (SEM), differential scanning calorimetry (DSC), and Fourier-transform infrared (FTIR) spectroscopy in the unexposed condition, and as-exposed to $253.7 \mathrm{~nm} \mathrm{UV}$ radiation. The creep compliance of PP LFT increased with increasing UV exposure, whereas the creep compliance of NY66 LFT showed a moderate decrease with increasing UV exposure. Moisture absorption experiments were performed in boiling water until saturation on NY66 and its LFT composites. Characterization of desorbed moisture absorption specimens suggested slight variation in the structure, and an analysis of creep compliances showed minimal changes as compared to the dry/unexposed specimens.
\end{abstract}

Keywords: Polymer Matrix Composites, Long Fiber Thermoplastics, Flexural Creep, Ultraviolet Radiation, Moisture Absorption, Infrared Spectroscopy

\begin{tabular}{llll}
\hline \multicolumn{2}{l}{ ABBREVIATIONS } & & \\
\hline ASTM & American Society for Testing and Materials & NY66 & Nylon 6,6 \\
DMA & Dynamic Mechanical Analysis & PMC & Polymer Matrix Composite \\
DSC & Differential Scanning Calorimeter & PP & Polypropylene \\
FTIR & Fourier-transform Infrared (spectroscopy) & SEM & Scanning Electron Microscopy \\
ISO & International Standards Organization & UV & Ultraviolet (radiation) \\
LFT & Long Fiber Thermoplastic & WLF & Williams-Landel-Ferry (equation) \\
LVDT & Linear Variable Displacement Transducer & & \\
\hline
\end{tabular}




\section{INTRODUCTION}

Long fiber thermoplastics (LFTs) are a class of discontinuous fiber-reinforced polymer matrix composites (PMCs) that are composed of a semi-crystalline thermoplastic matrix, and glass, carbon, or aramid fiber reinforcements with an aspect (length/diameter) ratio of about 200 to 3000 [1-3]. LFTs combine high stiffness, comparable processing costs, and comparable densities, making them more effective as automotive composites over short fiber $(l / d<100)$ thermoplastics $(\mathrm{SFTs})[4,5]$, which rely upon the matrix to carry the majority of applied load. LFTs exhibit viscoelasticity at all temperatures with a variable rate, especially around the matrix glass transition temperature $\left(T_{\mathrm{g}}\right)$ and approaching the melting temperature $\left(T_{\mathrm{m}}\right)$ [6]. Since the maximum service temperature of LFTs is near $200^{\circ} \mathrm{C}$, they are compliant due to viscoelasticity at moderate loads at these temperatures. Fiber reinforcements aid in increasing strength in LFTs compared to the neat matrix, and, since the fiber length is in excess of $0.8 \mathrm{~mm}$ [7], the critical fiber length requirement for load-transfer is met. The addition of fibers, however, causes a large interfacial area that may cause thermal mismatch [8], and capillarity [9], and may affect viscoelastic creep compliance. Thus, in spite of possessing an overall advantage over many competing materials, the mechanical performance of LFTs is function of its constituents and variables.

Fiber-reinforced thermoplastic composites in outdoor applications encounter ambient moisture and ultraviolet (UV) radiation in addition to stress and temperature, which affects mechanical properties. In polymers and PMCs, these variables cause degradation and affect their long-term strength. The extent of susceptibility varies with each polymer, depending on its fundamental functional group. However, moisture absorption and UV damage in some cases is beneficial, e.g., moisture absorption in polyamides increases their impact strength, and ultraviolet exposure may increase the strength if local crystallinity increases [10]. Hence, largely the base polymer controls the effect of environmental variables.

\subsection{Moisture Absorption}

Moisture absorption has been an area of concern since the introduction and subsequent large volume usage of glass fibers in fiber-reinforced composites, mainly in automotive applications. Moisture uptake 
causes increased mobility of the molecular chains and side groups, causing a reversible plasticization, which ultimately lowers the glass transition temperature $\left(T_{\mathrm{g}}\right)$ of the polymer. A permanent weight loss occurs because of chain dissociation or chain segmentation, which is referred as hydrolysis. In some cases, hydrolysis may cause material damage, such as microcracking, and accelerate moisture absorption. Moisture absorption causes a weakening of the fiber/matrix interface, leading to interfacial cracking, and causes swelling in the polymer matrix due to a dilatational strain caused by segmental relaxation.

Moisture absorption in PMCs follows Fickian absorption, pseudo-Fickian, or non-Fickian absorption/desorption behavior. As many authors have pointed out $[9,11]$, the Fickian kinetic model for moisture diffusion for some polymers is an inaccurate representation because the cumulative moistureinduced damage in the material is not incorporated [12].

The temperature dependence of the moisture absorption process is represented using an Arrhenius relation, $D(T)=D_{0} \exp (-A / R T)$, where the value of the pre-exponential constant $D_{0}$ is about $10^{-7} \mathrm{~mm}^{2} / \mathrm{s}$ at room temperature $\left(23^{\circ} \mathrm{C}\right)[13]$. The time for moisture saturation in plastics is dependent on the inverse of the square of the thickness $\left(t \alpha 1 / d^{2}\right)$ of the section.

Creep response of viscoelastic polymers and composites is strongly related with the moisture content and the overall diffusion process [14]. In time-dependent mechanical behavior of polymers, fluids of low molecular weight, e.g., water, exhibit equivalence with time similar to the Williams-Landel-Ferry (WLF) temperature equivalence. In case of water intake, an additional moisture-induced shift is applied to obtain master curves to estimate the long-term creep response.

In glass fiber-reinforced composites, a decrease in tensile strength after moisture absorption is typical [11]. However, this generalization may not be true for polyamides such as nylon 6 and nylon $6 / 6$ and their composites, which show improvements in Izod impact strength but show a decrease in tensile and flexural strengths [15]. On the other hand, polyolefins, such as polypropylene and high-density polyethylene remain unaffected with increasing water exposure due to a chemical structure with bonds that are difficult to hydrolyze. 
Many researchers have studied the effect of moisture absorption in fiber-reinforced composites. Previous studies report fiber matrix separation [9] and microcracking [16] that ultimately cause a decrease in tensile strength and elastic modulus. In contrast, various other studies report hygrothermal exposure to relax the processing-induced residual strains [17]. Consensus, however, has been established on decrease in $T_{\mathrm{g}}$ in thermoplastics [18].

\subsection{Ultraviolet Radiation and Photo-oxidation}

Photo-oxidation or photo-irradiation in polymers is dependent on the rate of oxygen diffusion. Photo-degradation in thermoplastic polymers causes the formation of ester, aldehyde, formate and propyl end groups [19]. The pendant methyl groups on alternate carbon atoms in the polypropylene backbone causes its lower resistance to photo-oxidation over high-density polyethylene. Loss of mechanical properties and optical properties (e.g., yellowing) are common effects in thermoplastics, such as in polyolefins and styrenic polymers, e.g., polystyrene. This degradation is directly proportional to irradiating light flux and radiation wavelength. Addition of a tensile stress to irradiation accelerates this degradation, whereas the addition of a compressive stress decelerates the damage propagation [20].

UV exposure may bring positive or negative changes to modulus locally [21], as the size of molecules that facilitate molecular motion undergoes a change. Conversely, an increase in local crystallinity causes a corresponding increase in modulus due to the formation of stiffer segments. Additionally, a decrease in density may also occur as small molecules undergo a phase change.

Thermoplastic polymers exhibit a decrease in strength with photo-degradation. Navarro et al. investigated artificial weathering and chemical degradation on injection-molded polypropylene and observed that after the induction time of degradation, compliance increased, which was attributed to increasing scission of chain molecules and the formation of oxidation products [21]. Goel et al. studied the effect of UV degradation on polypropylene and polypropylene/E-glass fiber LFT [10]. They reported a higher degree of crystallization in LFT composites as opposed to the neat polymer. In addition, an increase in the local modulus was observed in the UV-affected regions, which was attributed to the presence of chromophores in 
the fiber sizing. Surface cracking and discoloration in both the neat polymer and the LFT composite was observed.

Many mechanistic aspects of LFTs remain unclear in creep behavior. With some exceptions, the specific effect of ultraviolet (UV) exposure and moisture absorption on LFT creep response has rarely been reported. In this study, the effect of moisture absorption and ultraviolet radiation of nylon 6,6 , polypropylene and their LFT composites was investigated. To assess the rate of water intake, the extrusion/compression molded neat polymer (nylon 6/6) and LFT composite were completely immersed in water according to ASTM D-570 and ASTM D-5229M, after standard conditioning (ASTM D-618). To assess the effect of ultraviolet radiation, nylon 6/6 and polypropylene LFT composites were exposed to mid-ultraviolet lights in a UV reactor. The surface morphology of exposed specimens for both conditioning cases was observed using scanning electron microscopy and the composition of the surface was analyzed using Fourier-transform infrared spectroscopy. Post-exposure flexural creep and dynamic mechanical analysis (DMA) data was combined to estimate the long-term creep response. The scheme of experiments used in this study is discussed in detail in the following sections.

\section{EXPERIMENTAL METHODS}

\subsection{Materials}

Neat nylon 6/6 (NY66), neat polypropylene (PP), and their LFT composites were used in this study. These materials are listed in Table 1. All materials in this study were obtained as pellets from various vendors. A measured amounts of the pellets were extruded using a single-screw or a double-screw extruder with vendor-recommended barrel temperature profiles [22]. The extruded charge (extrudate) was compression-molded in a 400-ton capacity compression press as panels with the desired thickness. The residence time in the compression mold ranged from $20 \mathrm{~s}$ to $120 \mathrm{~s}$.

A three-layer morphology, i.e., the outer skin, the inner skin, and the core layers, is common for extrusion/compression molded composites [23]. The outer skin is polymer-rich and prone to the damage caused by extrusion and compression molding stresses, and particularly critical to the assessment of the 
effect of exposure, especially ultraviolet radiation, which adapts to the gradient generated by polymer flow at the surface during molding. In this study, this polymer-rich outer skin was removed using an end-mill, and only the fibrous inner skin was exposed to UV radiation.

\subsection{UV Exposure and Moisture Absorption}

The scheme of material preparation and testing is shown in Fig. 1. NY66, NY66 10 LFT, and NY66 40 LFT were tested in flexural creep configuration after UV exposure and moisture absorption, whereas PP and PP 40 LFT composite were exposed to UV radiation only and tested.

UV and visible light trigger degradation in polymers, with the near-UV radiation ( $290 \mathrm{~nm}$ to 400 $\mathrm{nm}$ ) being critical for the longevity in outdoor applications [19]. UV radiation is classified as a spectral category with wavelengths ranging in $100 \mathrm{~nm}$ to $400 \mathrm{~nm}$, according to the ISO 21348 standard [24]. In this study, a wavelength of approximately $253.7 \mathrm{~nm}$ was used [25], which is classified under the middle ultraviolet (MUV) category.

Test specimens were exposed to constant ultraviolet radiation in a test chamber with $16 \mathrm{UV}$ lights in a circular array. The flexural creep $(127.0 \mathrm{~mm} \times 12.7 \mathrm{~mm} \times 6.3 \mathrm{~mm})$ specimens were suspended at an equal distance $\left(38 \mathrm{~mm}\right.$ ) from the UV lights, which corresponds to an intensity of about $21000 \mathrm{~mW} / \mathrm{cm}^{2}$ at a radiation wavelength of $253.7 \mathrm{~nm}$ [26]. PP LFT flexural creep specimens were exposed to ultraviolet radiation for $100 \mathrm{~h}$ to $400 \mathrm{~h}$ duration, in $100 \mathrm{~h}$ increments. NY66 LFT specimens were exposed for $100 \mathrm{~h}$ to $400 \mathrm{~h}$ in $100 \mathrm{~h}$ increments and additionally for $3600 \mathrm{~h}$ to assess the effect of long-term UV irradiation.

Moisture absorption tests were designed according to requirements in ASTM D-570 and ASTM D5229M. ASTM D-5229M requires the sides (depth dimension) be sealed. In this study, all edges were exposed to water to determine the overall diffusivity of the material (ASTM D-570). The test specimens were completely immersed inside a glass vessel, and heating was provided by a shell heater with temperature control. The test apparatus is shown in Fig. 2. 
The weight of the specimens was measured using an electronic scale with precision of $0.0001 \mathrm{~g}$. Two specimen configurations were used; a) moisture absorption specimens of dimensions $76.2 \mathrm{~mm} \times 25.4 \mathrm{~mm} \times$ panel depth, and b) flexural creep specimens. These specimens were fully immersed in water until the specimens gained equilibrium moisture content, followed by desorption by drying in an aircirculated oven to regain equilibrium weight before a creep test.

\subsection{Fourier-Transform Infrared Spectroscopy}

The attenuated total reflectance (ATR) mode in FTIR (FTIR 4700, Thermo-Nicolet Corporation) was used in this study [27]. Twenty spectra in $400 \mathrm{~cm}^{-1}$ to $4000 \mathrm{~cm}^{-1}$ (mid-infrared) range were collected and averaged for each specimen condition.

\subsection{Differential Scanning Calorimetry}

In this study, a heating rate and cooling rate of $20^{\circ} \mathrm{C} / \mathrm{min}$ were used on a differential scanning calorimeter (DSC Q100, TA Instruments). The specimens for this method were sampled from the degraded surface with a mass $<15 \mathrm{mg}$. The specimens were sectioned using a blade from the edge of the degraded surface. This location ensured that the entirety of the specimen was representative of the material affected by the specific conditioning, i.e., UV or humidity.

\subsection{Scanning Electron Microscopy}

Specimens were made conductive by coating them with a layer of gold-palladium using the vacuum sputter-coating technique. A SEM (SEM 515, Philips Instruments) with accelerating voltages of $15 \mathrm{kV}$ or $20 \mathrm{kV}$ in the secondary electron contrast mode was used for imaging.

\subsection{Static Flexural Testing}

Static flexural testing was performed to determine the static flexural yield strength reported in Table 1. A testing frame (SATEC T-5000, Instron Inc.) according to ASTM D-790 [28] at a crosshead movement rate of $2.0 \mathrm{~mm} / \mathrm{min}$ with a span length of $96 \mathrm{~mm}$ and a span-to-depth ratio of 16:1. The results presented were averaged for five test specimens. 


\subsection{Flexural Creep Testing}

A creep testing fixture was fabricated for creep testing of specimens in flexural (bending) mode. The loading roller, support roller diameter, and span length met requirements in ASTM D-2990 and ASTM D$790[28,29]$. Flexural creep specimens were machined from compression molded plates to dimensions $127.0 \mathrm{~mm} \times 12.7 \mathrm{~mm} \times 6.3 \mathrm{~mm}$, as specified in ASTM D-2990 (ISO 899). The specimens were conditioned before testing according to ASTM D-618 (ISO 291).

A constant load was applied to the flexural creep specimens using dead weights. Displacement (or strain) was measured using a linear variable displacement transducer (LVDT) with a $-10 \mathrm{~V}$ to $+10 \mathrm{~V}$ range. Data points were acquired using a multiple-port data acquisition system that interfaced the LVDTs with a computer. The measured displacement was used to calculate a creep strain, $\varepsilon(t)$ and a creep compliance, $J(t)$, which is defined as the ratio of time-dependent strain, $\varepsilon(t)$ to the constant stress $\sigma_{0}$, is defined by Eqn. 1 .

$$
J(t)=\frac{b D(t) d^{3}}{P l^{3}}
$$

where $P$ is the applied load $(\mathrm{N}), l$ is the span length $(\mathrm{mm}), b$ is the specimen width $(\mathrm{mm}), d$ is the specimen depth (mm), and $D(t)$ is the creep deformation ( $\mathrm{mm})$. With some exceptions, creep data is acquired and reported as creep compliance, $J(t), 1 / \mathrm{MPa}$. For the flexural creep measurements, only the maximum creep strain in the tensile side of the specimen was recorded, according to ASTM D-2990 standard. Furthermore, the neutral axis of the specimens is assumed to be at the middle of the thickness $(d)$, which can be interpreted as the load $(P)$ remaining constant throughout the test.

The non-linear viscoelastic response of the LFTs was described with a four-parameter model [30] proposed by Hadid, Rechak and Zouani [31], as shown in Eqn. 2.

$$
\mathcal{E}(t)=a \sigma_{0}^{b} t^{c \exp (e \sigma)}
$$

where $\mathcal{E}(t)$ is the time-dependent strain $(\mathrm{mm} / \mathrm{mm}), a, b, c$, and $e$ are the model parameters, and $\sigma_{0}$ is the applied stress. 


\subsection{Dynamic Mechanical Analysis}

DMA specimens $(35.4 \mathrm{~mm} \times 12.7 \mathrm{~mm} \times 2.8 \mathrm{~mm})$ were tested in static creep mode in a dynamic mechanical analyzer (DMA 2980, TA Instruments) at a range of temperatures (Creep-TTS). The creep-TTS specimens were subject to a constant stress (about $33 \%$ of static flexural yield stress), in a temperature range of $23{ }^{\circ} \mathrm{C}$ to $90{ }^{\circ} \mathrm{C}$. A creep-recovery cycle was used at each temperature, allowing the specimen to recover for $15 \mathrm{~min}$ after creep at each temperature step.

\section{RESULTS AND DISCUSSION}

\subsection{Ultraviolet Exposure Degradation}

\subsubsection{PP LFT}

The immediate visual evidence of photo-oxidation is discoloration, which is caused because polyolefins oxidize in UV radiation. The degree of discoloration or yellowing depends on the degree of oxidation $[11,32]$. The discoloration was expected to be prominent in polypropylene due to its high susceptibility to photo-oxidation. These polymers are often compounded with a UV stabilizer for this reason.

Yellowing was observed, as shown in Fig. 3. The discoloration increased with increasing duration of exposure in PP (Fig. 3a), PP 40 LFT (Fig. 3b), and NY66 (Fig. 3c). In the fiber-reinforced composites, discoloration was observed in natural-colored composites; i.e., PP 40 LFT, whereas NY66 40 LFT was processed from black-colored pellets, discoloration was not expected.

Another visual aspect observed in UV exposed materials was surface cracking. Neat PP showed surface cracking at all exposure levels. The surface cracks in neat PP exposed for $200 \mathrm{~h}$ is shown in Fig. 4a. Micrographs of PP 40 LFT exposed for 200 h (Fig. 4b) show fibers resisting blister formation and crack growth. As the UV exposure duration increased ( $300 \mathrm{~h}$ to $400 \mathrm{~h}$ ), the crack sizes also increases, and is accompanied by fiber pullout from the fractured matrix, and matrix blistering (Fig. 4c-d), which causes a weight loss, e.g., the average weight loss in NY66 40 LFT with a $3600 \mathrm{~h}$ UV-exposure was approximately 2.5 wt. \% of the original weight. 
Overall, embrittlement exhibited at the surface and underlying layers occurs due to a reduction in volume that is caused by an increased crystallinity [21]. As the amorphous segments crystallize, a concomitant volume reduction occurs because of a) ordering of polymer segments and b) formation of degradation products such as esters, which cause cracking in the degraded matrix.

\subsubsection{FTIR Analysis}

FTIR spectra suggested the formation of various degradation products, as shown in the appearance of the fingerprint region. Figure 5 shows the FTIR spectra for specimens exposed at increasing durations of UV radiation. With increasing exposure, the narrow peaks seen in the unexposed specimen broadened, which led to overlap, lower intensity or disappearance. This change is very visible in the wavenumbers ranging from $2800 \mathrm{~cm}^{-1}$ to $3000 \mathrm{~cm}^{-1}$ and from $800 \mathrm{~cm}^{-1}$ to $1200 \mathrm{~cm}^{-1}$.

The carbonyl peak in the spectra showed increased intensity with increasing exposure time, as shown in Fig. 6. Additionally, the peak at $1720 \mathrm{~cm}^{-1}$ was observed to divide into two peaks at $1711 \mathrm{~cm}^{-1}$ and $1726 \mathrm{~cm}^{-1}$. Furthermore, for $400 \mathrm{~h}$ exposure, additional peaks were observed. The increasing intensity of the carbonyl peaks is an indicator of photo-oxidation [33]. In this case, multiple peaks at $\sim 1720 \mathrm{~cm}^{-1}$ is consistent with findings in [34], representing the formation of a carboxylic acid or an ester.

With the increase in UV exposure in PP LFT, the carbonyl $\left(1713 \mathrm{~cm}^{-1}\right)$ absorbance and hydroxyl $\left(3300 \mathrm{~cm}^{-1}\right)$ absorbance showed a corresponding increase (Fig. 7). This increase in absorbance of carbonyl and hydroxyl groups suggests an ongoing photo-degradation and formation of lower molecular weight oxidation products. Specifically, photo-oxidation that initiates with the consumption of residual additives (such as anti-oxidants), is followed by the initiation and the progression of oxidation, causing the formation of low molecular weight products with carbonyl and hydroxyl radicals, which cause an increase in their absorbance [33].

\subsubsection{Crystallinity Analysis}

Percent crystallinity values are calculated by taking the ratio of absorbance at peaks of $972 \mathrm{~cm}^{-1}$ and $997 \mathrm{~cm}^{-1}$ [35]. The peak intensity at $997 \mathrm{~cm}^{-1}$, which is related to the vibration of helical structure of the $\alpha$ - 
phase crystalline phase increases with oxidation, and the peak intensity of $972 \mathrm{~cm}^{-1}$ remains constant [36]. The absorbance of the exposed specimens in the $900 \mathrm{~cm}^{-1}$ to $1100 \mathrm{~cm}^{-1}$ region in the FTIR spectra shows the two peak intensities (Fig. 8). The crystallinity values obtained from this method are listed under FTIR in Table 2. Crystallinity showed a minor change with an increase in exposure time. A slight decrease in crystallinity with increased exposure, however, is apparent from the plot. As photo-oxidation progresses in a semi-crystalline polymer, the crystalline region degrades due to cross-linking and the amorphous region undergoes chain scission. The segmented chains often undergo secondary crystallization; these crystalline regions can cause restriction of chain mobility due to branching [33, 37].

Percent crystallinity values were also calculated from the ratio of the heat of crystallization $\left(\Delta H_{\mathrm{f}}\right)$ of the degraded specimen with the heat of crystallization of a $100 \%$ crystalline reference $\left(\Delta H_{\mathrm{f}}{ }^{*}\right)$, using Eqn. 3 .

$$
\% X_{C}=\left(\Delta H_{f} / \Delta H_{f}^{*}\right) \times 100
$$

The percentage crystallinity values obtained by this method are reported under DSC in Table 2 . The crystallinity values calculated from this method remained nearly constant during $100 \mathrm{~h}$ to $400 \mathrm{~h}$ exposure range, with a slight increase in the $200 \mathrm{~h}$ to $400 \mathrm{~h}$ range.

\subsubsection{Creep Response}

Flexural creep testing of the exposed specimens showed an increased creep compliance with increasing exposure time, as shown in Fig. 9. As observed, the creep compliance at $1000 \mathrm{~s}$ is about $33 \%$ higher for $400 \mathrm{~h}$ exposure than $100 \mathrm{~h}$ exposure. In addition, the margin of increase is higher beyond the $200 \mathrm{~h}$ exposure time. This trend in creep compliance induced by UV exposure for PP 40 LFT is similar to the effect of increasing temperature. Initial resistance to polymer segmental motion or chain sliding due to increased local crystallinity is weak or absent, which is confirmed by comparing elastic strain, which showed an average of $(70.0 \pm 1.2) \%$ increase with UV exposure at the four exposure conditions at a constant load of about $64 \mathrm{~N}$. 


\subsubsection{NY66 LFT}

\subsubsection{Scanning Electron Microscopy}

An SEM micrograph of NY66 40 LFT exposed for $3600 \mathrm{~h}$ is shown in Fig. 10a. UV irradiation caused substantial weathering at the surface, with apparent degradation of the matrix and dissociation of fiber ends. Additionally, brittle cracking (Fig. 10b) on the polymer surface are evident. Brittle cracking occurred due to high homogeneity in NY66, which is accompanied by crazing.

\subsubsection{FTIR Analysis}

NY66 40 LFT showed a decrease in absorbance with an increase in UV exposure, as shown in Fig. 11a. Specifically, a decrease in peak intensity and overlap is seen, which can be attributed to the formation of various degradation products. In the $3300 \mathrm{~cm}^{-1}$ (hydroxyl) band, a mixed intensity variation was seen. In pigmented polyamides such as NY66 40 LFT, the oxidation is limited to the surface layers, as the pigments limit oxygen diffusion. The variation of oxygen allowed to diffuse causes a corresponding variation in number of degradation products. For photo-oxidation to progress in polymers that do not allow easy permeation of oxygen to the bulk of the material, thin sections ( micrometer) are required [38]. Also, the absorption of UV and visible light in polyamides facilitates the formation of a surface oxide layer that inhibits the further permeation of oxygen into the bulk of the material [19]. Conversely, the random degradation mechanisms in polyolefins produce a greater number of degradation products, whereas oxidation in polyamides [39] advances by the transformation of $\mathrm{N}$-vicinal methylene radical that reacts with oxygen, further causing the formation of peroxy radicals. The peroxy radicals may isomerize or adapt to one of many possible reactions, which cause chain-scission of carboxyl/carbonyl end groups. Overall, photo-oxidation in polyamides is restricted to the surface layers, with low oxygen permeation and increased resistance to oxygen permeation by UV-reflecting pigments and the presence of a surface oxide layer.

The FTIR spectra of specimens conditioned with prolonged UV exposure (Fig. 11b) show severe matrix degradation and barely show any characteristic polymer bands in the FTIR spectrum. As observed, the $3600 \mathrm{~h}$ exposed and E-glass fiber spectra have approximately similar peaks. This observation is further 
supported by the SEM micrographs in Fig. 10a-b, which show polymer erosion and exposed fibers at the surface.

The characteristic bands of a polyamide show a decrease in absorbance with an increase in exposure, as shown in Fig. 12. Specifically, the amide peaks (amide-I, amide-II) at $1522 \mathrm{~cm}^{-1}$ and $1630 \mathrm{~cm}^{-1}$ show lower intensity peaks with an increase in UV exposure (Fig. 12a). The peak intensities of amide-VI $\left(575 \mathrm{~cm}^{-1}\right)$ and amide-V $\left(675 \mathrm{~cm}^{-1}\right)$ also exhibit a decrease. The decrease of NY66 characteristic linkages refers to the structural variations and confirms the formation of new products, with an overall loss of amide groups. The hydroxyl group, which is expected to increase with increasing UV exposure, showed a variable absorbance (Fig. 12c). The $3300 \mathrm{~cm}^{-1}$ absorbance remained nearly constant until $300 \mathrm{~h}$ of exposure, increased at $400 \mathrm{~h}$ and decreased again at $3600 \mathrm{~h}$, with no visible peak. The change in hydroxyl formation from $300 \mathrm{~h}$ to $400 \mathrm{~h}$ signifies the presence of an incubation period that exceeds $300 \mathrm{~h}$. The prolonged exposure to UV radiation may have caused an increase in oxygen permeation and thus, photo-oxidation.

On an average, a decrease in the carbonyl and hydroxyl absorbance is seen with increasing UV exposure (Fig. 13). This decrease can be explained by considering a low permeation of oxygen to the polyamide matrix and a low rate of photo-oxidation. However, an overall change in molecular structure of the surface is evident.

\subsubsection{Crystallinity Analysis}

Percentage crystallinity was calculated using the DSC heat of crystallization data and is reported under DSC in Table 2. Crystallinity remained nearly constant between $100 \mathrm{~h}$ to $400 \mathrm{~h}$ and decreased slightly at a $3600 \mathrm{~h}$ exposure, which confirms the minimal effect of UV exposure on the pigmented NY66. This effect on crystallinity is because of the constriction of oxidation to the surface layers and availability of oxygen in the section $(d>6.0 \mathrm{~mm})$.

\subsubsection{Creep response}

In flexural creep, a decrease in creep compliance with increasing UV exposure was observed. As seen in Fig. 14a, the creep compliance followed the opposite trend with increasing UV exposure, with the 
$3600 \mathrm{~h}$ UV-exposed NY66 40 LFT showing the least creep compliance, and the $100 \mathrm{~h} \mathrm{UV}$ exposed NY66 40 LFT showing the most creep compliance. The unexposed NY66 40 LFT (0 h) showed creep compliance similar to $300 \mathrm{~h}$ to $400 \mathrm{~h} \mathrm{UV}$-exposed material. Clearly, the increasing UV exposure caused changes in crystallinity due to crystallization at the glass fiber interface, and have been reported to cause local resistance [10] to reduced polymeric segmental motion and consequent decrease in deformation. Creep compliance increased in $0 \mathrm{~h}$ to $300 \mathrm{~h}$ range in the UV-exposed material. Crystallinity often increases with increasing UV exposure, but the crystallized molecules offer hindrance after a maximum, which lowers crystallinity. Since the intensity in this study was about $21000 \mathrm{~mW} / \mathrm{cm}^{2}$, about $100 \%$ higher than in Ref. [35], this maximum most likely occurred in the $0 \mathrm{~h}$ to $100 \mathrm{~h}$ range, followed by a decrease as shown using a dashed line in Fig. 14b. Since this effect is only limited to the surface ( $<10 \%$ of the thickness), the advantage of crystallinity in decreasing the creep compliance and in aiding local strength is realized only after $300 \mathrm{~h}$ of incubation. As this sustained UV radiation-induced crystallinity changes only after induction, an increased resistance to deformation is achieved degradation is confined to the surface, and oxygen permeation is partially inhibited. The bulk of the material remains free of oxidation and changes in crystallinity, along with low oxygen diffusion.

\subsection{Moisture Absorption}

Moisture absorption is a function of functional groups in the chemical structure, e.g., the ratio of $\mathrm{CH}_{2} / \mathrm{CONH}$ of the polymer $[13,40]$. Polyolefins show low water uptake since they have fewer hydrolysable bonds. In this study, with $24 \mathrm{~h}$ of boiling water $\left(100^{\circ} \mathrm{C}\right)$ conditioning on NY66 $(10 \mathrm{wt} . \%$ and $40 \mathrm{wt} . \% \mathrm{E}-$ glass) LFTs showed an approximately $2.4 \%$ to $3.9 \%$ weight gain, whereas neat PP and PP 40 LFT showed about a $0.06 \%$ to $0.09 \%$ weight gain, which confirms their low moisture absorption behavior. PP and PP LFT were thus excluded from the moisture absorption study.

\subsubsection{Water Absorption Kinetics}

NY66 and its LFT composites (10 LFT and 40 LFT) showed a constant moisture gain before they reached steady-state equilibrium moisture content, as shown in Fig.15a. The moisture diffusion coefficient at $T=100{ }^{\circ} \mathrm{C}$, calculated using regression for NY66 was $4.7 \times 10^{-5} \mathrm{~m}^{2} / \mathrm{s}, 4.0 \times 10^{-5} \mathrm{~m}^{2} / \mathrm{s}$ for NY66 $10 \mathrm{LFT}$, and 
$5.6 \times 10^{-5} \mathrm{~m}^{2} / \mathrm{s}$ for NY66 40 LFT. The average weight gain in 15 days $(360 \mathrm{~h})$ of moisture absorption at $23{ }^{\circ} \mathrm{C}$ was about $0.9 \%$ of the initial weight, with a diffusion coefficient of $4.7 \times 10^{-6} \mathrm{~m}^{2} / \mathrm{s}$, calculated using average equilibrium moisture content from boiling water immersion experiment. The equilibrium moisture content is independent of conditioning temperature, at a constant moisture exposure level (complete immersion).

Figure $15 \mathrm{~b}$ shows the areal swelling coefficient, $\beta=\Delta$ (cross-section) $/ \Delta$ (moisture-content) of the three materials. This areal swelling coefficient is an extension of the dimensional swelling coefficients defined in Ref. [12]. The absorption of moisture causes an increase in the free volume of the material. The value of $\beta$ increases with increasing moisture content and increasing exposure time. The $\beta$ value remains nearly constant for the neat polymer and NY66 40 LFT, as both are homogenous. As the NY66 10 LFT has low fiber content, the polymer-rich and fiber-rich regions cause variations in the rate of water intake and a slight variation in $\beta$.

The neat polymer and the LFT composites follow Fickian moisture kinetics. The non-steady state water diffusion in polymers is represented by the Fick's second law of diffusion, given by Eqn. 4 .

$$
\frac{\partial c}{\partial t}=D \frac{\partial^{2} c}{\partial z^{2}}
$$

where $c$ corresponds to moisture concentration, $D$ is the diffusion coefficient, $z$ is distance, and $t$ is time. Water transport kinetics in materials that absorb moisture in pure diffusion is expected to obey the general solution of Eqn. 4. A comparison of the Fickian absorption model (Eqn. 5 - 6) and the experimental data are shown in Fig. 16.

$$
\begin{array}{r}
G(T, t)=1-\exp \left[-7.3\left(D(T) t / h^{2}\right)^{0.75}\right] \\
M(T, t)=M_{b}+G(T, t)\left(M_{m}-M_{b}\right)
\end{array}
$$


where $G(T, t)$ is the moisture absorption/desorption function representing Fickian diffusion, $D(T)$ is the diffusivity coefficient at temperature $T, t$ is the exposure time, $h$ is the specimen depth, $M(T, t)$ is moisture content of the material, $M_{m}$ is the moisture equilibrium content, and $M_{b}$ is the baseline moisture content in the material.

The low value of $\beta$ indicates a predominantly diffusion-controlled water intake (Fig. 15b). In addition, a minimum $60 \%$ of the equilibrium moisture content was observed to follow a linear uptake of water as a function of square root of conditioning time $\left(\mathrm{h}^{1 / 2}\right)$. A very low rate of absorption $\left(\sim 10^{-5} \mathrm{~m}^{2} / \mathrm{s}\right.$ at $100{ }^{\circ} \mathrm{C}$ ) is observed, which confirms the presence of purely diffusion-controlled absorption [40]. A mixed diffusion/relaxation-controlled diffusion was observed by Thomason et al. [12] at $T=120^{\circ} \mathrm{C}$.

\subsubsection{Differential Scanning Calorimetry}

DSC thermograms showed a marginal change in the average melting temperature of moistureexposed NY66 $\left(259^{\circ} \mathrm{C}\right)$, NY66 10 LFT $\left(263^{\circ} \mathrm{C}\right)$, and NY66 40 LFT $\left(264^{\circ} \mathrm{C}\right)$, all specimens being sampled from the exposed surface. In contrast to the UV-exposed specimens, the melting behavior for moistureexposed specimens were observed to show slight changes from the unexposed NY66 $\left(262{ }^{\circ} \mathrm{C}\right)$ and unexposed NY66 40 LFT $\left(262{ }^{\circ} \mathrm{C}\right)$. For example, the melting temperature for the NY66 40 LFT $3600 \mathrm{~h} \mathrm{UV}$-exposed is $256{ }^{\circ} \mathrm{C}$, whereas for moisture-saturated NY66 40 LFT, it is $264{ }^{\circ} \mathrm{C}$. A near constant melting point suggests a reversible change in the polymer structure for moisture-exposed specimens, such as plasticization. In the case of UV-exposed specimens, the surface damage is irreversible, causing a slight shift in melting temperatures, consistent with weight loss, SEM evaluation, and a decrease in the FTIR absorbance.

\subsubsection{FTIR}

The FTIR spectra of the desorbed specimens are shown in Fig. 17. Overall, the changes brought about by water saturation were considered reversible in nature in this study. Only a slight change in transmittance was seen in the three materials after saturation (Fig. 17). Saturation most probably caused a plasticization of the matrix, rather than hydrolysis, which may cause permanent structural changes. As seen in Fig. 17e, a slight change in intensity of the hydroxyl group is seen from the saturation. This change may be 
due to the decrease in the number of recombined bonds in the structure, which may adapt to a different configuration than the original structure [41].

\subsubsection{Surface Damage}

Figure 18a-b show the NY66 40 LFT surface that underwent exposure in boiling water at $100{ }^{\circ} \mathrm{C}$ for more than $100 \mathrm{~h}$. The polymer surface (Fig. 18a) shows microcracking after exposure to saturation, whose evolution can be attributed to the release of residual stresses from compression molding, when the moisture penetrates into the stressed regions and causes plasticization. The evolution of cracking at the polymer surface causes an additional increase in the free volume of the material, facilitating an increased rate of moisture absorption. The polymer at the surface shows whitening because the residual stresses are released from the bulk of the material, and cracks the surface, which is accompanied by a) shear and b) craze formation [27]. Specifically, whitening is a function of the craze formation at the crack-tip, which causes the formation of a region with a different refractive index than the unaffected regions [26]. As shown in Fig. 18b, the static flexure failure in NY66 40 LFT exhibits interfacial stress whitening and clear stretched regions that suggest the release of residual compressive stresses and crazing. Additionally, the evolution of microvoids is evident at the failure surface, further aiding in the failure in static flexure (ASTM D-790).

\subsubsection{Time-Temperature-Stress Superposition}

Time-temperature-stress superposition (TTSSP) was performed to estimate the long-term creep response of the materials under chosen conditions of temperature and immersion humidity. The procedure is explained in an earlier work . In this study, flexural creep and DMA creep-TTS tests were performed on postsaturated and dried specimens at $23{ }^{\circ} \mathrm{C}, 50{ }^{\circ} \mathrm{C}, 70{ }^{\circ} \mathrm{C}$, and $90{ }^{\circ} \mathrm{C}$ temperatures. The creep-TTS data from DMA was superimposed using vendor software, and the horizontal shift factors $\left(a_{\mathrm{T}}\right)$ were calculated using the Williams-Landel-Ferry equation for the four temperature values $\left(23^{\circ} \mathrm{C}\right.$ to $\left.90^{\circ} \mathrm{C}\right)$. At a chosen temperature value, the flexural creep curves were plotted on creep compliance versus reduced time (time $/ a_{\mathrm{T}}$ ), where the $a_{\mathrm{T}}$ corresponds to the creep-TTS superposition. The vertical mismatch in the creep curves was addressed by applying a vertical shift factor $\left(b_{\mathrm{T}}\right)$. As verified in a previous study [42], a high positive correlation was observed with the long-term tests and the TTSSP data. 
The flexural creep compliance for NY66 (Fig. 19) increases by about $25 \%$ from $50{ }^{\circ} \mathrm{C}$ to $90{ }^{\circ} \mathrm{C}$ at $t$ $=100 \mathrm{~s}$. In addition, creep compliance is about three times higher for the neat polymer than for the NY66 10 LFT at $100 \mathrm{~s}$, and it continued to increase with the increasing time of exposure. The trend in the moisture-absorbed NY66 LFT is identical to increasing temperature, as discussed in a previous study [30]. This similarity confirms the equivalence of humidity and temperature with time. Moreover, the irreversible nature of moisture is observed, as the creep compliance for the NY66 40 LFT is nearly equivalent at $50{ }^{\circ} \mathrm{C}$ for moisture-exposed and unexposed specimens at $t=10^{4} \mathrm{~s}$.

\section{$4 \quad$ SUMMARY AND CONCLUSIONS}

UV exposure studies were conducted on PP and PP-LFTs, and UV exposure and moisture absorption studies were conducted on NY66 and NY66-LFT. The following conclusions can be drawn from this study:

- Yellowing was observed in natural colored materials, whereas all materials showed surface cracking with increasing UV exposure

- Creep compliance of UV-exposed PP LFT increased, whereas the creep compliance of NY66 40 LFT moderately decreased with increases in UV exposure.

- FTIR suggests an induction period for photo-oxidation, between $300 \mathrm{~h}$ to $400 \mathrm{~h}$ of UV exposure.

- Creep compliances of UV-exposed NY66 40 LFT decreased due to low oxidation rates, as crystallinity remained approximately constant.

- NY66 and its LFT composites followed a diffusion-controlled (Fickian) moisture absorption.

- The desorbed specimens showed variable FTIR absorbance, indicating structural changes by moisture absorption.

- The TTSSP of the desorbed specimens confirmed an equivalence of moisture and temperature in creep resistance, as they showed a similar superposition behavior as the unexposed specimens subjected to different temperatures.

\section{ACKNOWLEDGEMENTS}

The authors appreciate the financial assistance for the current investigation received through Prof. Uday K. Vaidya. The authors would also like to acknowledge the technical assistance received from Dr. 
Moncy Jose, Ms. Reginna Scarber, Dr. Robin Griffin, Dr. Selvum Pillay, Mr. Andy Grabany, and Dr. Haibin

Ning.

\section{REFERENCES}

1. Balaji Thattaiparthasarathy K, Pillay S, Ning H, Vaidya UK. Process simulation, design and manufacturing of a long fiber thermoplastic composite for mass transit application. Compos Part A. 2008;39(9):1512-1521.

2. Bartus SD, Vaidya UK, Ulven CA. Design and Development of a Long Fiber Thermoplastic Bus Seat. J Thermoplast Mater. 2006;19(2):131-154.

3. Vaidya UK, Serrano JC, Villalobos A, Sands J, Garner J. Design and analysis of a long fiber thermoplastic composite tailcone for a tank gun training round. Mater \& Des. 2008;29(2):305-318.

4. Markarian J. Long fibre reinforced thermoplastics continue growth in automotive. Plast Addit Compd. 2007;9(2):20-22, 24.

5. Musselman M. Automotive composites : A design and manufacturing guide. 2nd Ed. Wheat Ridge, CO: Ray Publishing, 2006.

6. Kroschwitz JI, Mark HF. Encyclopedia of polymer science and technology. 3rd Ed. Hoboken, N.J.: Wiley-Interscience, 2003.

7. Thomason JL, Vlug MA. Influence of fibre length and concentration on the properties of glass fibrereinforced polypropylene: 1. Tensile and flexural modulus. Compos Part A. 1996;27(6):477-484.

8. Thomason JL, Groenewoud WM. The influence of fibre length and concentration on the properties of glass fibre reinforced polypropylene: 2. Thermal properties. Compos Part A. 1996;27(7):555-565.

9. Pillay S, Vaidya UK, Janowski GM. Effects of moisture and UV exposure on liquid molded carbon fabric reinforced nylon 6 composite laminates. Compos Sci Tech. 2009;69(6):839-846.

10. Goel A, Chawla KK, Vaidya UK, Koopman M, Dean DR. Effect of UV exposure on the microstructure and mechanical properties of long fiber thermoplastic (LFT) composites. J Mater Sci. 2008;43(13):4423-4432.

11. Scheirs J. Compositional and Failure Analysis of Polymers: A Practical Approach. Hoboken, NJ: John Wiley \& Sons, 2000.

12. Thomason JL. Structure-property relationships in glass-reinforced polyamide, Part 3: Effects of hydrolysis ageing on the dimensional stability and performance of short glass-fiber-reinforced polyamide 66. Polym Compos. 2007;28(3):344-354.

13. Weitsman YJ, Elahi M. Effects of Fluids on the Deformation, Strength and Durability of Polymeric Composites - An Overview. Mech Time-depend Mater. 2000;4(2):107-126.

14. Bond DA, Smith PA. Modeling the Transport of Low-Molecular-Weight Penetrants Within Polymer Matrix Composites. Appl Mech Rev. 2006;59(5):249-268.

15. http://www2.basf.us//plasticsweb/displayanyfile?id=0901a5e180004880. (Accessed: 10 February, 2009).

16. Springer GS, Ed. Environmental effects on composite materials. Westport, CT: Technomic, 1984.

17. Chawla KK. Composite Materials : Science and Engineering. 2nd Ed. New York, NY: Springer, 2001.

18. Allen RC, Bauer RS. Moisture-Related Failure. Materials Park, OH: ASM International, 2003.

19. Singh B, Sharma N. Mechanistic implications of plastic degradation. Polym Degrad Stabil. 2008;93(3):561-584.

20. Tyler DR. Mechanistic aspects of the effects of stress on the rates of photochemical degradation reactions in polymers. J Macromol Sci-Polym Rev. 2004;C44(4):351-388.

21. Navarro R, d'Almeida J, Rabello M. Elastic properties of degraded polypropylene. J Mater Sci. 2007;42(6):2167-2174.

22. http://tools.ticona.com/tools/mcbasei/product-tools.php?sPolymer=\&sProduct=. (Accessed: 21 May, 2007). 
23. Sarraf AG, Tissot H, Tissot P, Alfonso D, Gurny R, Doelker E. Influence of hot-melt extrusion and compression molding on polymer structure organization, investigated by differential scanning calorimetry. J Appl Poly Sci. 2001;81(13):3124-3132.

24. http://www.spacewx.com/pdf/SET_21348_2004.pdf. (Accessed: 19 October, 2008).

25. http://www.rayonet.org/word\%20pages/Microsoft\%20Word\%20-\%20RPR-200.pdf. (Accessed: 19 October, 2008).

26. Hadal R, Yuan Q, Jog JP, Misra RDK. On stress whitening during surface deformation in claycontaining polymer nanocomposites: A microstructural approach. Mater Sci Engg: A. 2006;418(12):268-281.

27. Notomi M, Kishimoto K, Shibuya T, Koizumi T. Effects of moisture absorption on fracture behaviors of acrylonitrile-butadiene-styrene resin. J Appl Polym Sci. 1999;72(3):435-442.

28. ASTM D-790: Standard test methods for flexural properties of unreinforced and reinforced plastics and electrical insulating materials. Annual Book of Standards. Vol. 08.01. West Conshohocken, PA: ASTM International, 2003.

29. ASTM D-2990: Standard Test Methods for Tensile, Compressive, and Flexural Creep and CreepRupture of Plastics. Annual Book of Standards. Vol. 08.01. West Conshohocken, PA: ASTM International, 2003.

30. Chevali VS, Dean DR, Janowski GM. Flexural creep behavior of discontinuous thermoplastic composites: Non-linear viscoelastic modeling and time-temperature-stress superposition. Compos Part A. 2009;40(6-7):870-877.

31. Hadid M, Rechak S, Zouani A. Empirical nonlinear viscoelastic model for injection molded thermoplastic composite. Polym Compos. 2002;23(5):771-778.

32. Chanda M, Roy SK. Plastics Technology Handbook. Boca Raton, FL:CRC Press, 2006.

33. Hamid S, Amin M, Maadhah A, Eds. Handbook of Polymer Degradation. Boca Raton, FL:CRC Press, 2000.

34. Fernando SS, Christensen PA, Egerton TA, White JR. Humidity dependence of carbon dioxide generation during photodegradation of biaxially oriented polypropylene in oxygen. Polym Degrad Stabil. 2009;94(1):83-89.

35. Karger-Kocsis J. Polypropylene : An A-Z reference. London, UK:Kluwer Academic Publishers, 1999.

36. Law A, Simon L, Lee-Sullivan P. Effects of thermal aging on isotactic polypropylene crystallinity. Polym Engg Sci. 2008;48(4):627-33.

37. Khraishi N, Al-Robaidi A. Effect of weathering on UV-stabilized low density polyethylene films (LDPE) for a multilayer greenhouse cover. Polym Degrad Stabil. 1991;32(1):105-114.

38. Tang L, Sallet D, Lemaire J. Photochemistry of polyundecanamides. 1. Mechanisms of photooxidation at short and long wavelengths. Macromol. 1982;15(5):1432-1437.

39. Gröning M, Hakkarainen M. Headspace solid-phase microextraction -- a tool for new insights into the long-term thermo-oxidation mechanism of polyamide 6.6. J Chromatogr-A. 2001;932(1-2):1-11.

40. Bond DA, Smith PA. Modeling the Transport of Low-Molecular-Weight Penetrants Within Polymer Matrix Composites. Appl Mech Revi. 2006;59:249-268.

41. Bond DA. Moisture Diffusion in a Fiber-reinforced Composite: Part I - Non-Fickian Transport and the Effect of Fiber Spatial Distribution. J Compos Mater. 2005;39(23):2113-2141.

42. Chevali VS. Flexural creep of long fiber thermoplastic composites: Effect of constituents and variables on viscoelasticity. Birmingham, AL: The University of Alabama at Birmingham; 2009.

43. http://www.rtpcompany.com/info/data/long/VLF80207EMHS.htm. (Accessed: 15 April, 2007).

44. http://www.matweb.com. (Accessed: May 18, 2007).

45. http://www.rtpcompany.com/info/data/index.htm. (Accessed: May 18, 2007).

\section{FIGURE CAPTIONS}

Fig. 1. A schematic of experiments performed in the current study.

Fig. 2. A drawing of the water immersion apparatus used for moisture absorption tests. 
Fig. 3. Stereographs acquired under visible light for specimens exposed to increasing durations of UV radiation: a) Neat PP, b) PP 40 LFT, and c) Neat NY66. Discoloration is compared here only for natural-colored materials.

Fig. 4. Surface characteristics of a) neat PP UV-exposed for $200 \mathrm{~h}$, b) PP LFT UV-exposed for $200 \mathrm{~h}$, c) PP LFT UV-exposed for $300 \mathrm{~h}$, and d) PP LFT UV-exposed for $400 \mathrm{~h}$.

Fig. 5. FTIR/ATR spectra obtained for unexposed and UV-exposed PP 40 LFT for the durations of $100 \mathrm{~h}$ to $400 \mathrm{~h}$.

Fig. 6. FTIR spectra of PP 40 LFT showing formation of convoluted peaks with increase in UV exposure.

Fig. 7. Absorbance of PP 40 LFT at carbonyl $\left(1713 \mathrm{~cm}^{-1}\right)$ and hydroxyl $\left(3300 \mathrm{~cm}^{-1}\right)$ regions with increasing UV exposure.

Fig. 8. FTIR spectra showing the absorbance of peaks at $997 \mathrm{~cm}^{-1}$ and $972 \mathrm{~cm}^{-1}$ at various exposure times.

Fig. 9. Creep compliance plotted as a function of time for PP $40 \mathrm{LFT}$ exposed to UV at $0 \mathrm{~h}$ to $400 \mathrm{~h}$ durations at $40{ }^{\circ} \mathrm{C}\left(=T_{g}+40^{\circ} \mathrm{C}\right)$.

Fig. 10. Scanning electron micrographs of surface damage in NY66 40 LFT exposed to UV irradiation for $3600 \mathrm{~h}$, showing a) fiber pullout at surface, and b) shredding (fibril formation) and strain whitening.

Fig. 11. FTIR/ATR spectra of NY66 40 LFT a) exposed to UV radiation for various intervals and b) a comparison of unexposed, $3600 \mathrm{~h} \mathrm{UV}$ exposed, and E-glass fibers.

Fig. 12. FTIR/ATR spectra of UV-irradiated NY66 40 LFT showing a) Amide-I $\left(1630 \mathrm{~cm}^{-1}\right)$ and Amide-II $\left.\left(1522 \mathrm{~cm}^{-1}\right), \mathrm{b}\right)$ Amide V $\left(675 \mathrm{~cm}^{-1}\right)$ and Amide-VI $\left(575 \mathrm{~cm}^{-1}\right)$ bands, and c) Hydroxyl group (3300 $\left.\mathrm{cm}^{-1}\right)$.

Fig. 13. Absorbances of NY66 40 LFT carbonyl $\left(1713 \mathrm{~cm}^{-1}\right)$ and hydroxyl $\left(3300 \mathrm{~cm}^{-1}\right)$ bands plotted with an increasing UV exposure time.

Fig. 14. (a) Flexural creep compliance for unexposed ( $0 \mathrm{~h})$ and UV exposed (100 h to $3600 \mathrm{~h})$ NY66 40 LFT tested at $90{ }^{\circ} \mathrm{C}\left(=T_{\mathrm{g}}+40^{\circ} \mathrm{C}\right)$, and (b) the variation of polymer crystallinity with increasing UV exposure time. The dashed line represents the common trend of crystallinity variation with UV exposure.

Fig. 15. Change in a) weight gain with progressing water immersion time and b) areal swelling coefficient.

Fig. 16. A comparison of Fickian moisture absorption model to the experimental data that shows a close fit.

Fig. 17. FTIR spectra of water-saturated NY66, NY66 10 LFT, and NY66 40 LFT. Fingerprint region peaks, a) $-\mathrm{CH}_{2}$ rocking, $730 \mathrm{~cm}^{-1}$, b) $-\mathrm{CH}_{2}$ asymmetric stretching, $2930 \mathrm{~cm}^{-1}$. Functional group peaks, c) Carbonyl, $-\mathrm{C}=\mathrm{O}, 1720 \mathrm{~cm}^{-1}$, d) Amide-I, $-\mathrm{NH}_{2}, 1630 \mathrm{~cm}^{-1}$. Hydroxyl $(-\mathrm{OH})$ band for e) saturated and unexposed NY66 40 LFT and f) Hydroxyl group for the three materials, $3300 \mathrm{~cm}^{-1}$.

Fig. 18. Matrix crazing observed on surface of specimens immersed in boiling water.

Fig. 19. Time-temperature-stress superposition curves for post-saturation NY66, NY66 10 LFT, and NY66 40 LFT at a) $50{ }^{\circ} \mathrm{C}$, b) $70{ }^{\circ} \mathrm{C}$, and c) $90{ }^{\circ} \mathrm{C}$. 


\section{TABLES}

Table 1. Material properties of the base polymers and LFT composites tested in this study [22, 43-45].

\begin{tabular}{|c|c|c|c|c|c|}
\hline & Commercial Grade & $\begin{array}{c}T_{\mathrm{g}} \\
\left({ }^{\circ} \mathrm{C}\right) \\
\end{array}$ & $\begin{array}{c}T_{\mathrm{m}} \\
\left({ }^{\circ} \mathrm{C}\right) \\
\end{array}$ & $\begin{array}{c}\rho \\
\left(\mathrm{kg} / \mathrm{m}^{3}\right) \\
\end{array}$ & $\begin{array}{c}\sigma_{\mathrm{f}} \\
(\mathrm{MPa}) \\
\end{array}$ \\
\hline NY66 & RTP200 & & & 1140 & 107 \\
\hline NY66 10 LFT & - & 50 & 265 & 1200 & 120 \\
\hline NY66 40 LFT & VLF80207EM-HS & & & 1460 & 338 \\
\hline HDPE & HDPS-0250-E & & & 950 & 24 \\
\hline HDPE 10 LFT & - & -30 & & 1010 & 30 \\
\hline HDPE 40 LFT & CELSTRAN PEHD-GF40-01 & & & 1270 & 61 \\
\hline PP & PPST-0250-E & & & 915 & 36 \\
\hline PP 40 LFT & CELSTRAN PP-GF40-02 & & & 1210 & 127 \\
\hline
\end{tabular}

Table 2. A list of percentage crystallinity values calculated using 1) DSC and 2) the $972 \mathrm{~cm}^{-1}$ and $992 \mathrm{~cm}^{-1}$ peaks in FTIR, for PP 40 LFT.

\begin{tabular}{cccc}
\hline \multirow{2}{*}{ Exposure time (h) } & \multicolumn{3}{c}{ Crystallinity (\%) } \\
\cline { 2 - 4 } & NY66 40 LFT & \multicolumn{2}{c}{ PP 40 LFT } \\
\cline { 2 - 4 } & DSC & DSC & FTIR \\
\hline 0 & 34.1 & 35.5 & -- \\
100 & 27.3 & 30.8 & 94.9 \\
200 & 22.5 & 27.3 & 99.6 \\
300 & 22.1 & 29.5 & 97.5 \\
400 & 21.8 & 31.2 & 95.1 \\
3600 & 20.1 & -- & -- \\
\hline
\end{tabular}




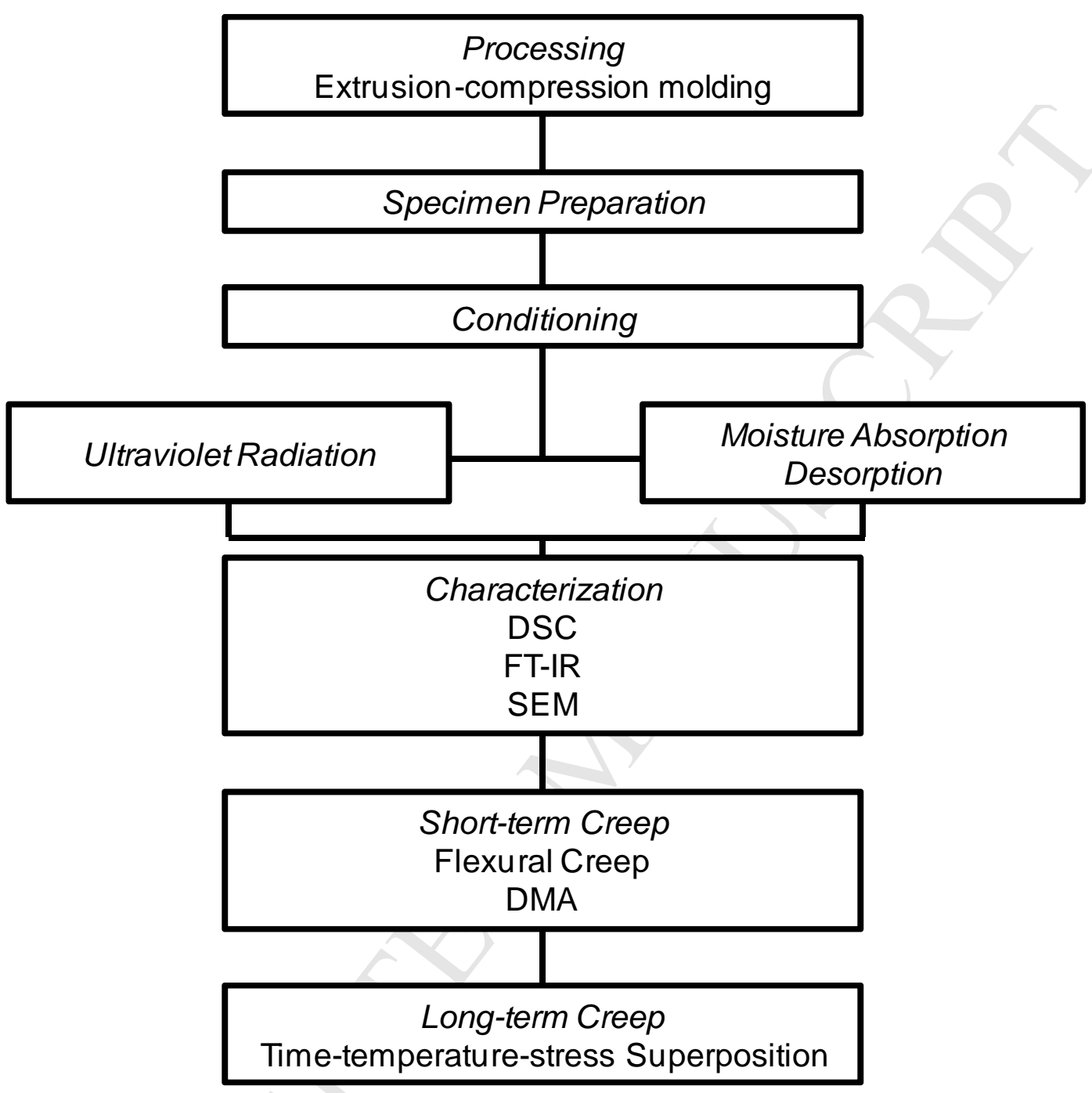

Fig. 1. A schematic of experiments performed in the current study. 


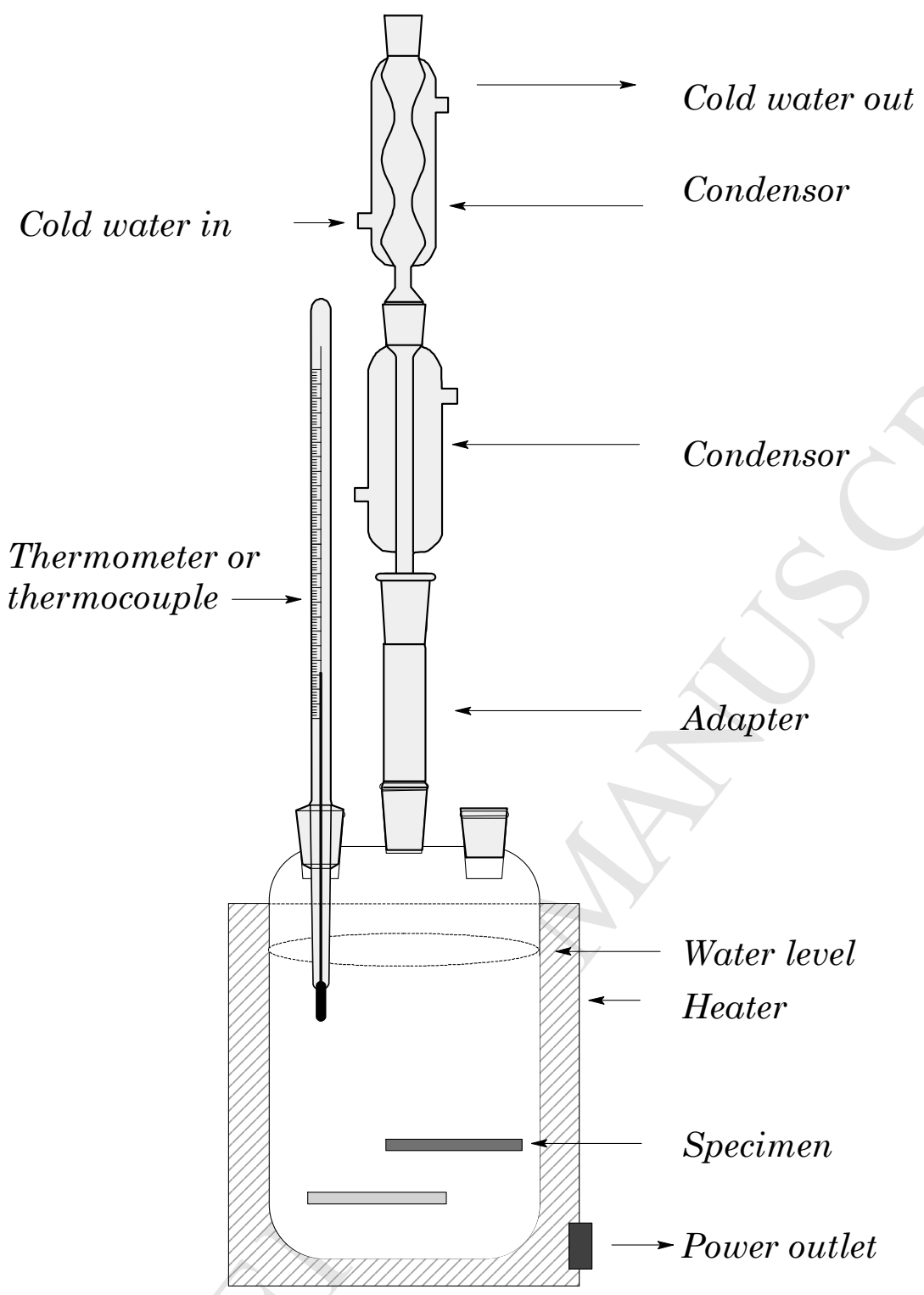

Fig. 2. A drawing of the water immersion apparatus used for moisture absorption tests. 


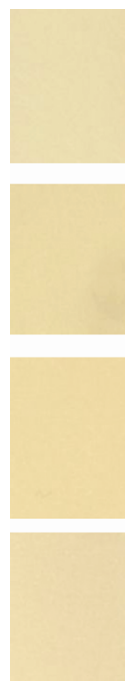

(a)

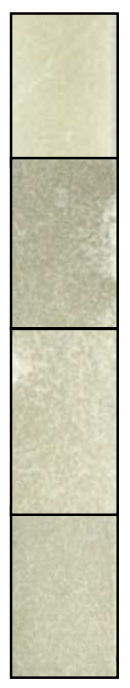

(b)

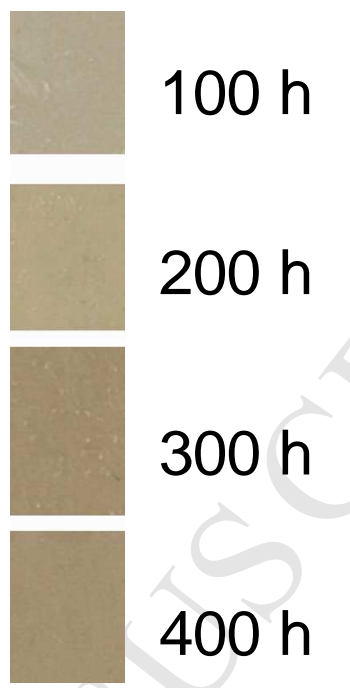

(c)

Fig. 3. Stereographs acquired under visible light for specimens exposed to increasing durations of UV radiation: a) Neat PP, b) PP 40 LFT, and c) Neat NY66. Discoloration is compared here only for natural-colored materials. 

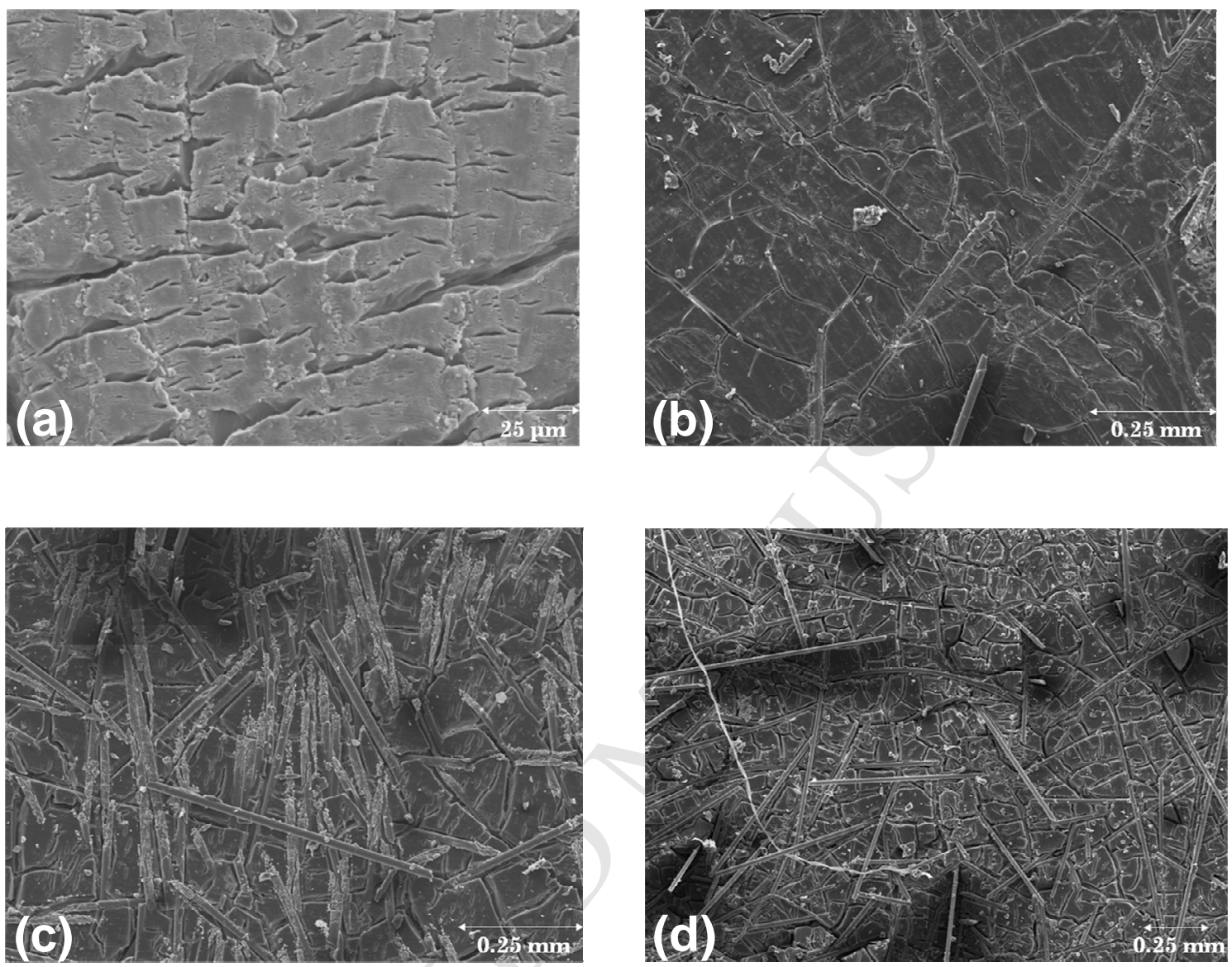

Fig. 4. Surface characteristics of a) neat PP UV-exposed for $200 \mathrm{~h}, \mathrm{~b}$ ) PP LFT UV-exposed for 200 $\mathrm{h}, \mathrm{c})$ PP LFT UV-exposed for $300 \mathrm{~h}$, and d) PP LFT UV-exposed for $400 \mathrm{~h}$. 


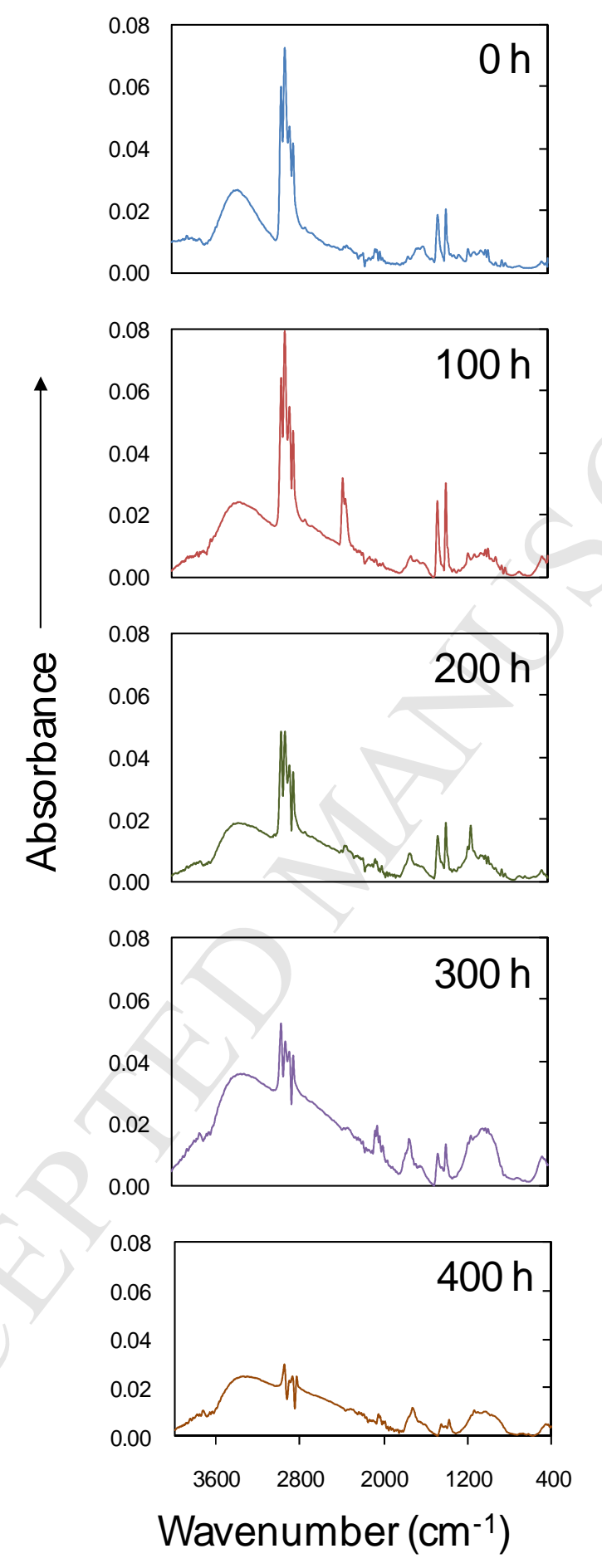

Fig. 5. FTIR/ATR spectra obtained for unexposed and UV-exposed PP 40 LFT for the durations of $100 \mathrm{~h}$ to $400 \mathrm{~h}$. 


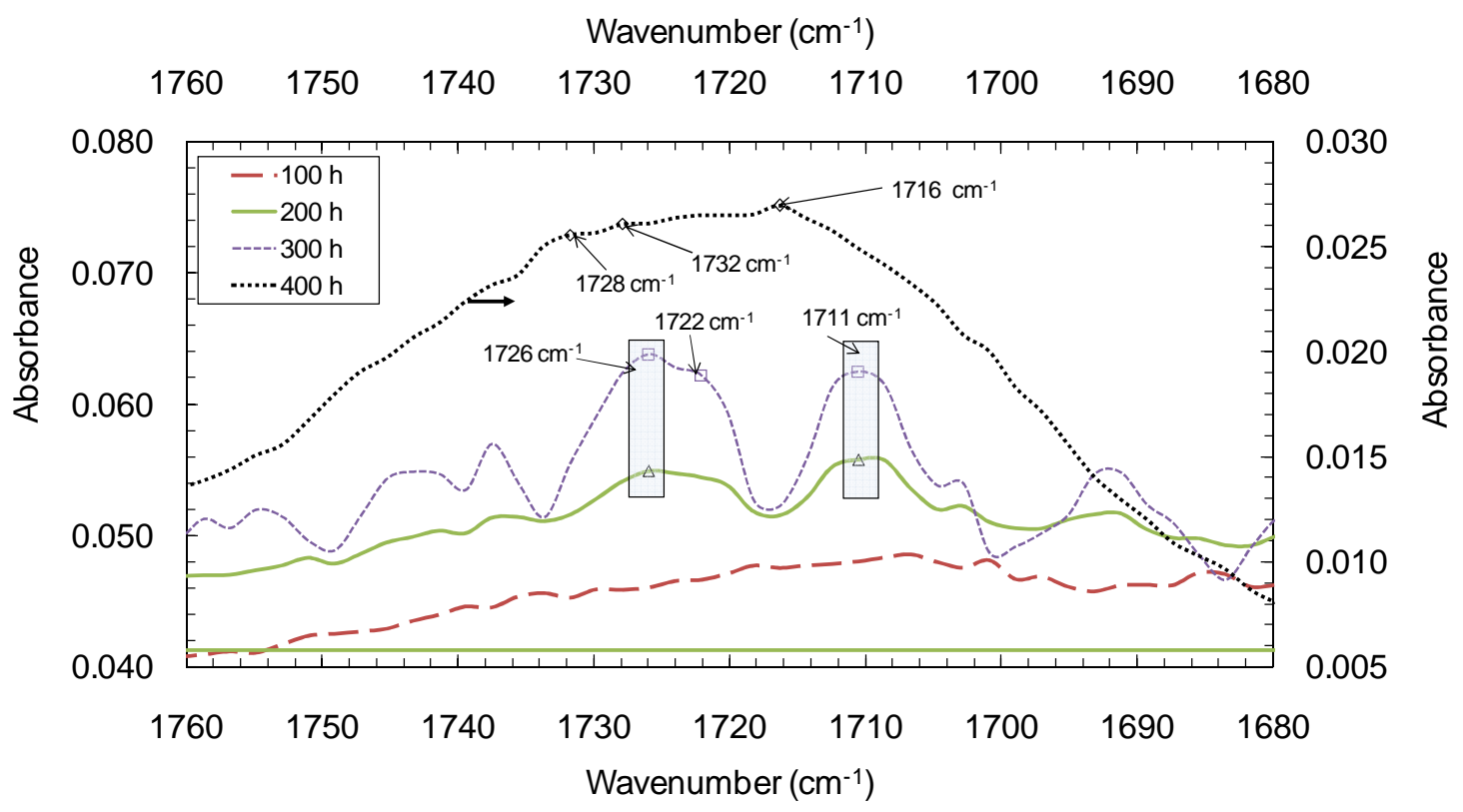

Fig. 6. FTIR spectra of PP 40 LFT showing formation of convoluted peaks with increase in UV exposure.

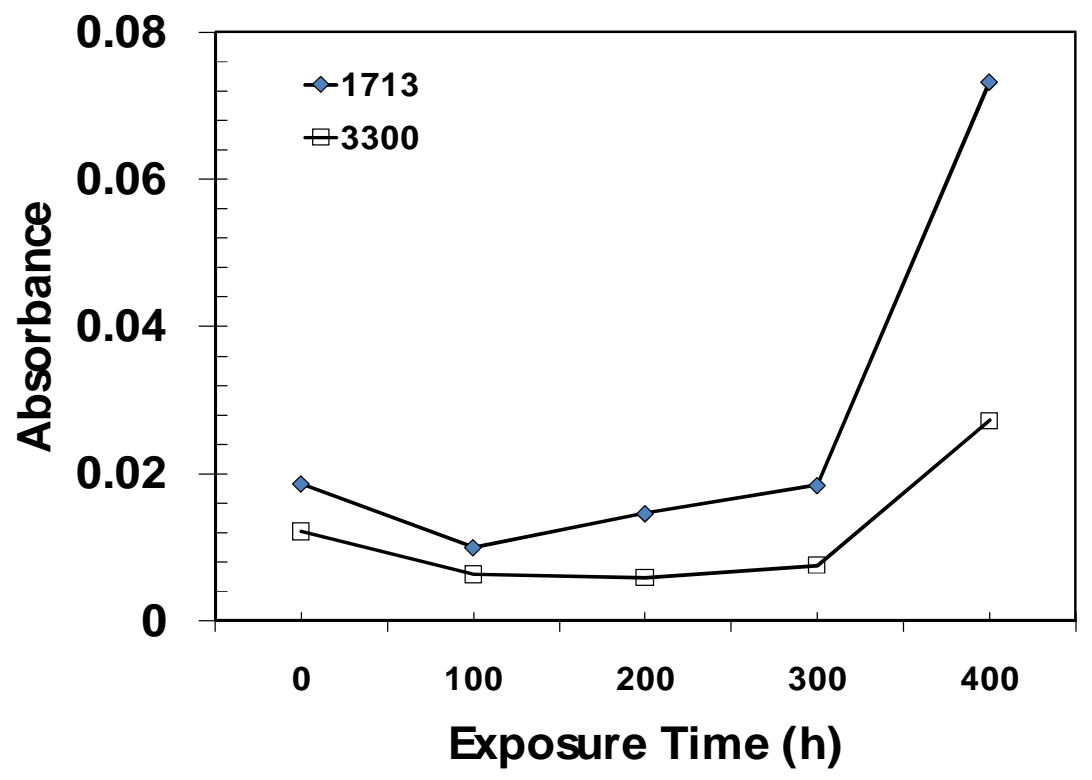

Fig. 7. Absorbance of PP 40 LFT at carbonyl $\left(1713 \mathrm{~cm}^{-1}\right)$ and hydroxyl $\left(3300 \mathrm{~cm}^{-1}\right)$ regions with increasing UV exposure. 


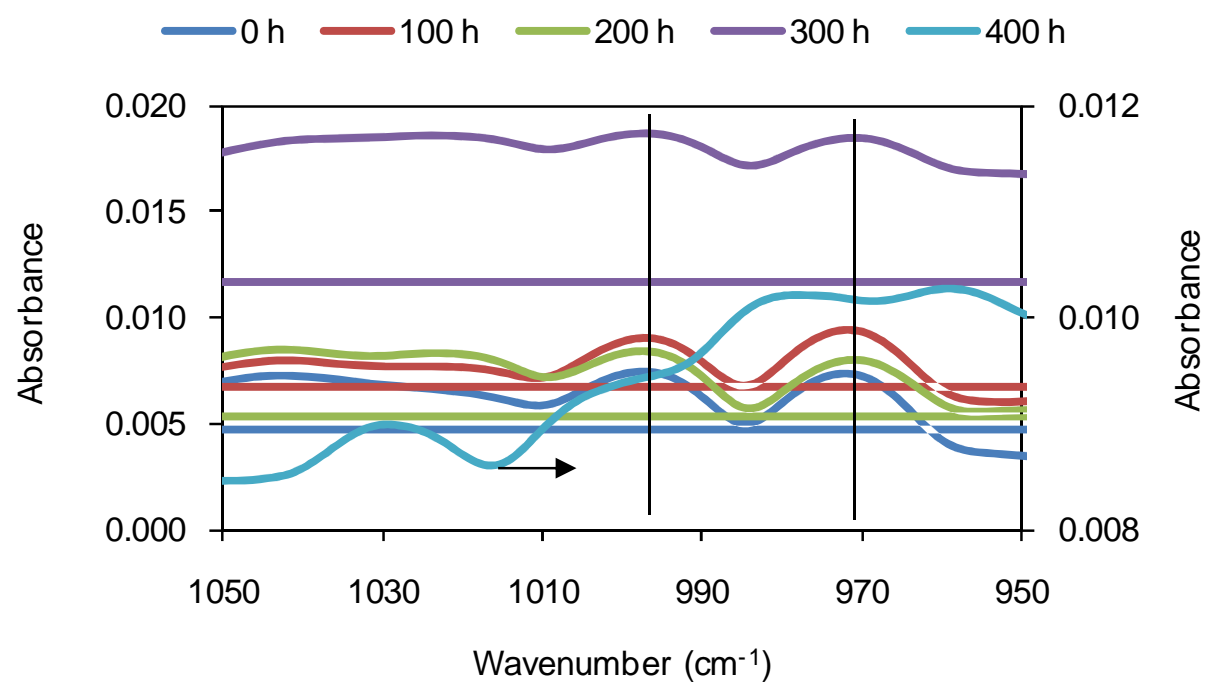

Fig. 8. FTIR spectra showing the absorbance of peaks at $997 \mathrm{~cm}^{-1}$ and $972 \mathrm{~cm}^{-1}$ (vertical bars) at various exposure times.

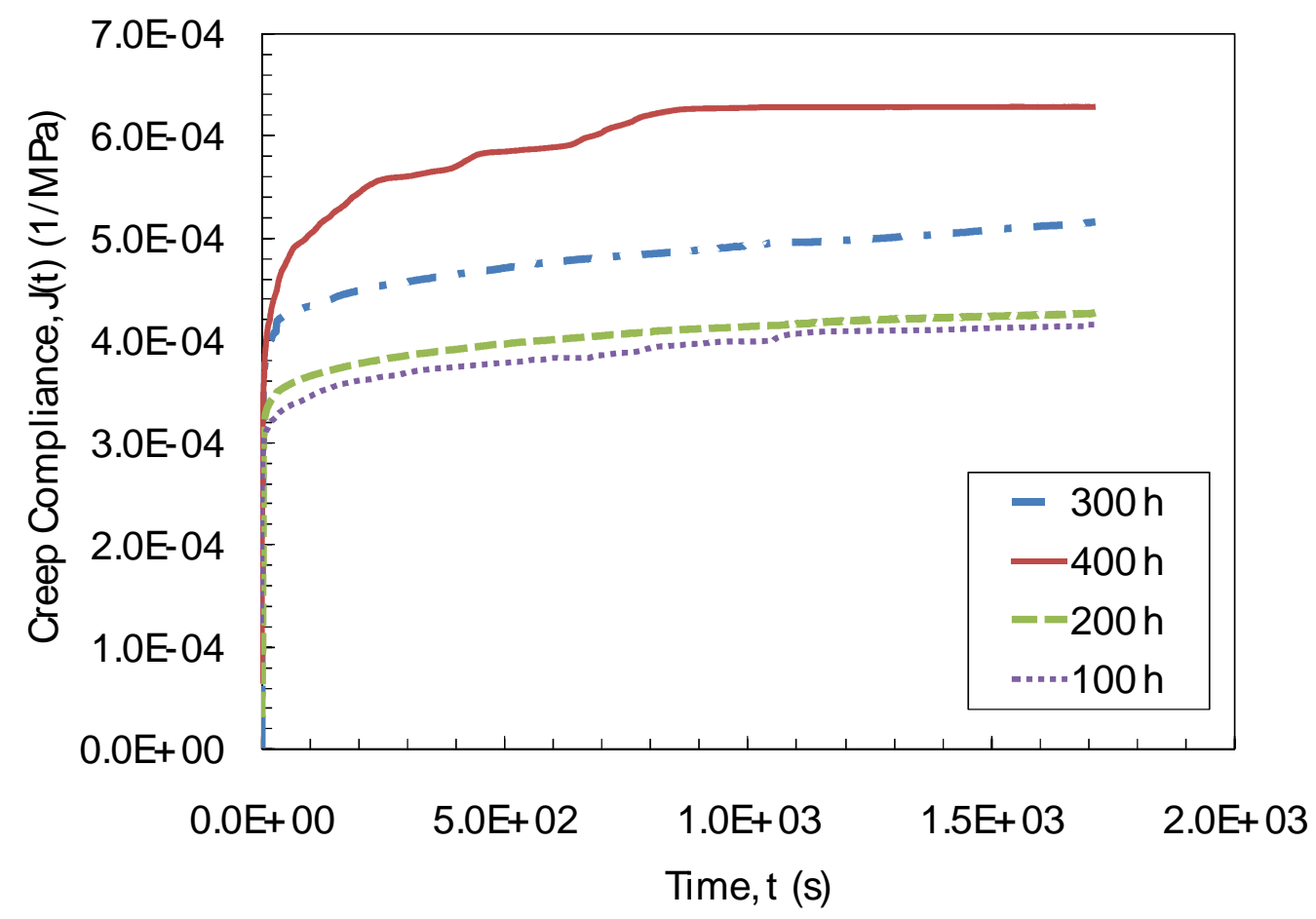

Fig. 9. Creep compliance plotted as a function of time for PP 40 LFT exposed to UV at $0 \mathrm{~h}$ to $400 \mathrm{~h}$ durations at $40{ }^{\circ} \mathrm{C}\left(=T_{g}+40^{\circ} \mathrm{C}\right)$. 

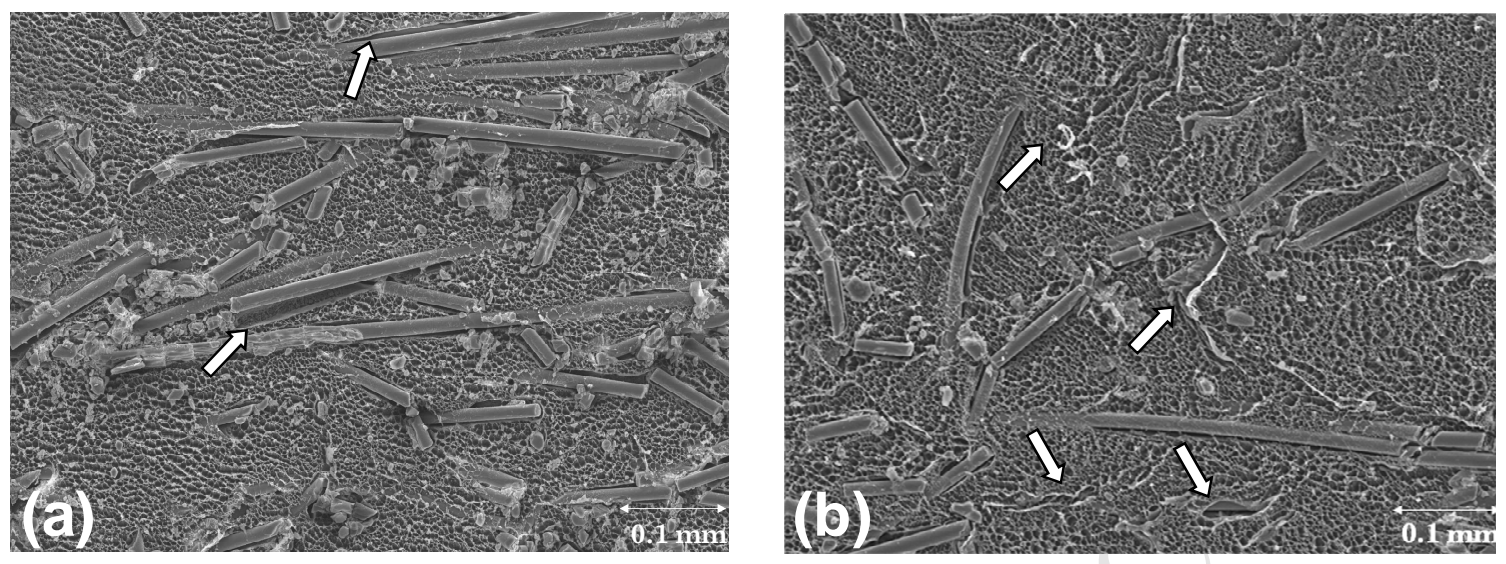

Fig. 10. Scanning electron micrographs of surface damage in NY66 40 LFT exposed to UV irradiation for $3600 \mathrm{~h}$, showing a) fiber pullout at surface, and b) shredding (fibril formation) and strain whitening. 

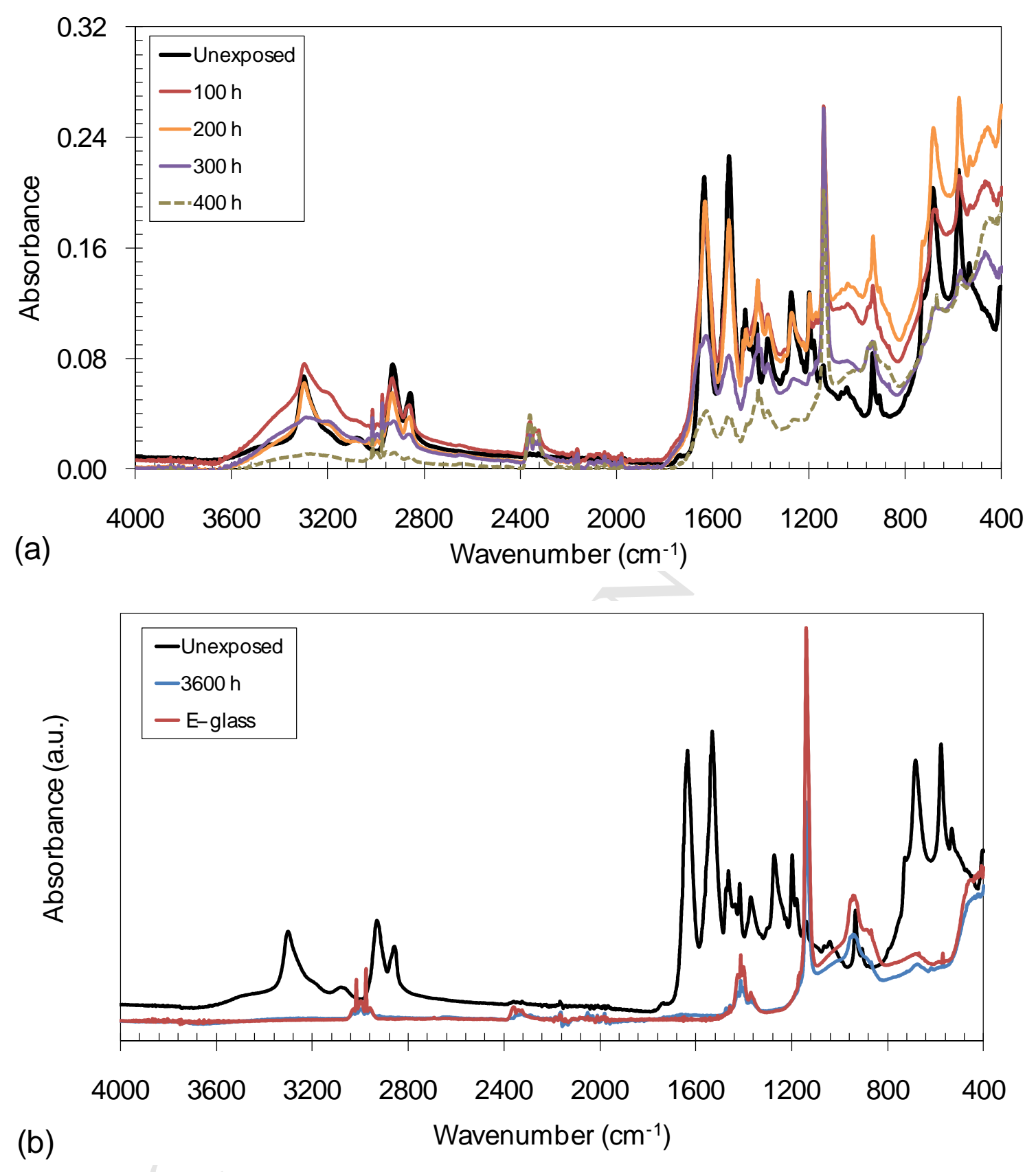

Fig. 11. FTIR/ATR spectra of NY66 40 LFT a) exposed to UV radiation for various intervals and b) a comparison of unexposed, $3600 \mathrm{~h} \mathrm{UV}$ exposed, and E-glass fibers. 

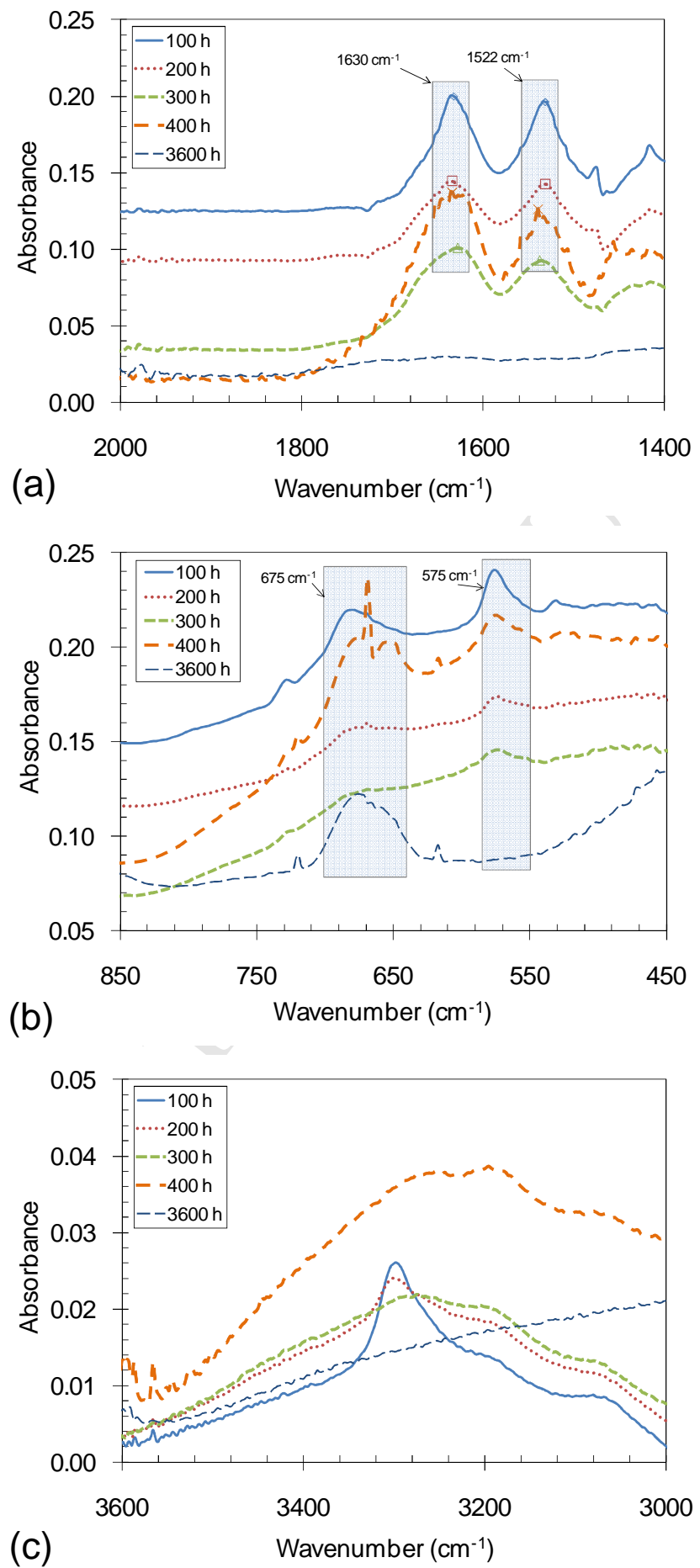

Fig. 12. FTIR/ATR spectra of UV-irradiated NY66 40 LFT showing a) Amide-I $\left(1630 \mathrm{~cm}^{-1}\right)$ and Amide-II $\left(1522 \mathrm{~cm}^{-1}\right)$, b) Amide V $\left(675 \mathrm{~cm}^{-1}\right)$ and Amide-VI $\left(575 \mathrm{~cm}^{-1}\right)$ bands, and c) Hydroxyl group $\left(3300 \mathrm{~cm}^{-1}\right)$. 


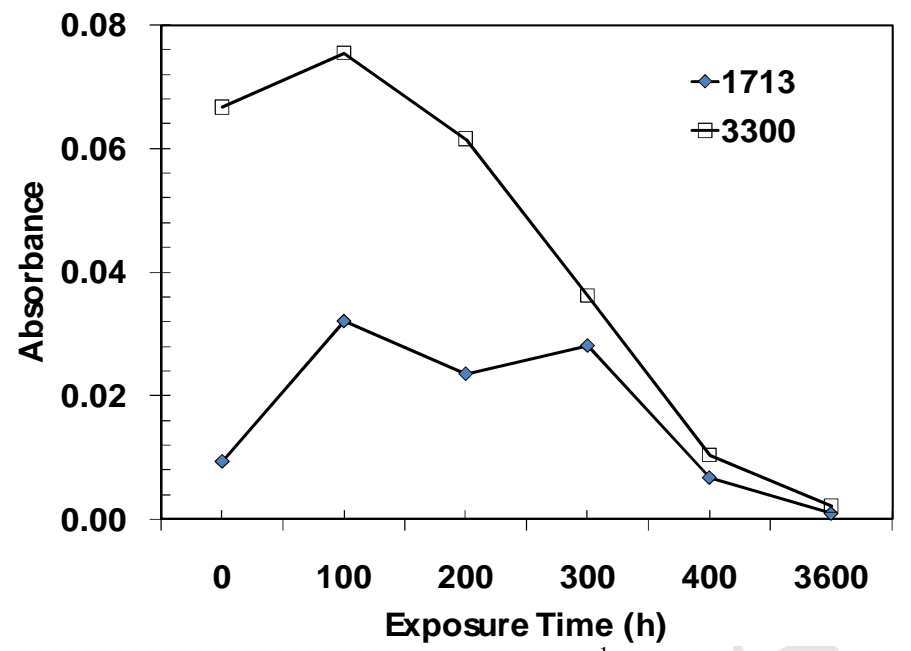

Fig. 13. Absorbances of NY66 40 LFT carbonyl $\left(1713 \mathrm{~cm}^{-1}\right)$ and hydroxyl $\left(3300 \mathrm{~cm}^{-1}\right)$ bands plotted with an increasing UV exposure time. 

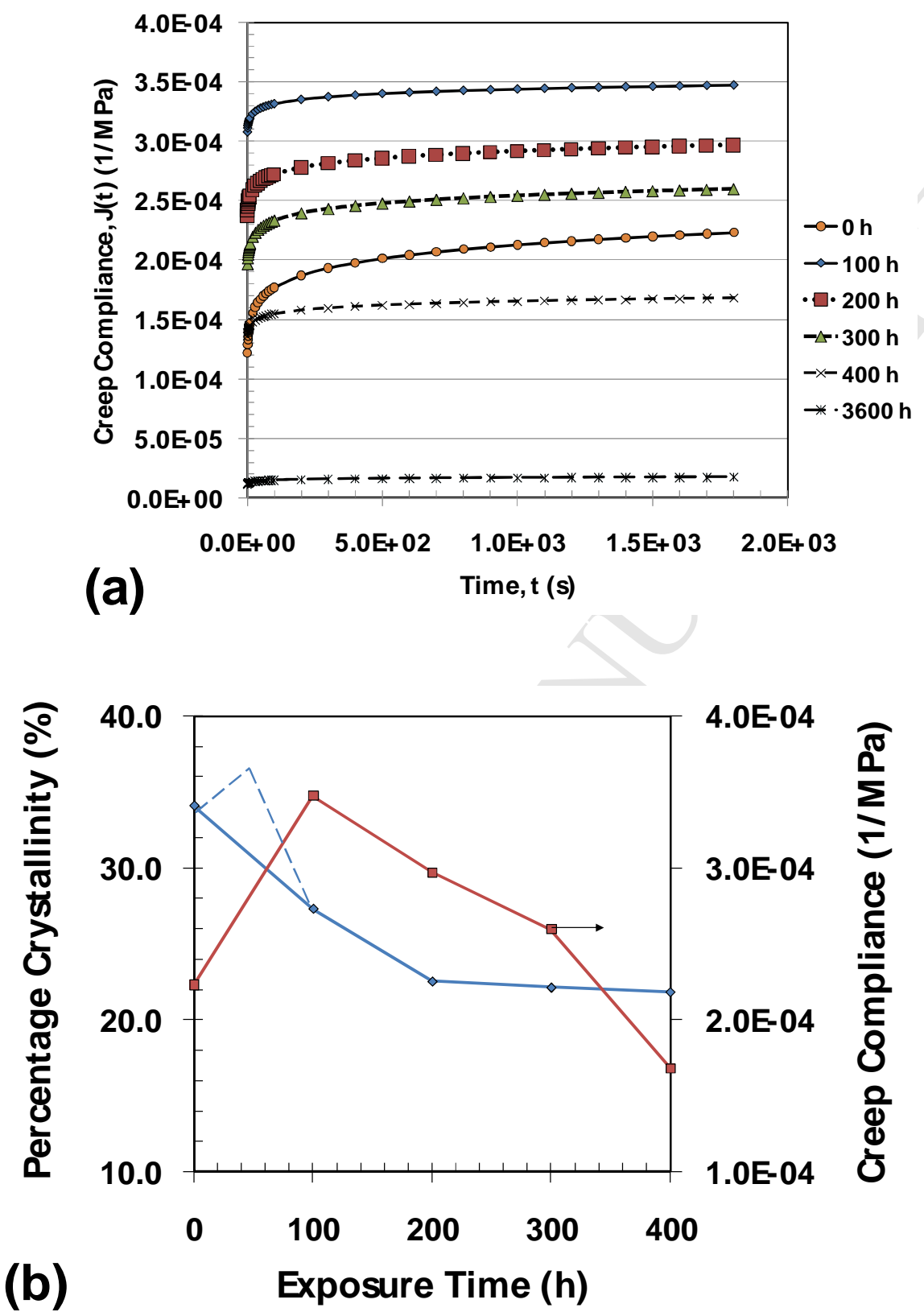

(b)

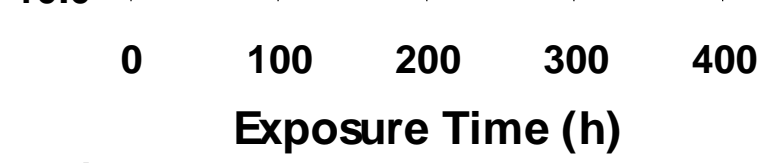

Fig. 14. (a) Flexural creep compliance for unexposed ( $0 \mathrm{~h})$ and UV exposed ( $100 \mathrm{~h}$ to $3600 \mathrm{~h}$ ) NY66 40 LFT tested at $90{ }^{\circ} \mathrm{C}\left(=T_{\mathrm{g}}+40{ }^{\circ} \mathrm{C}\right)$, and (b) the variation of polymer crystallinity with increasing UV exposure time. The dashed line represents the common trend of crystallinity variation with UV exposure. 

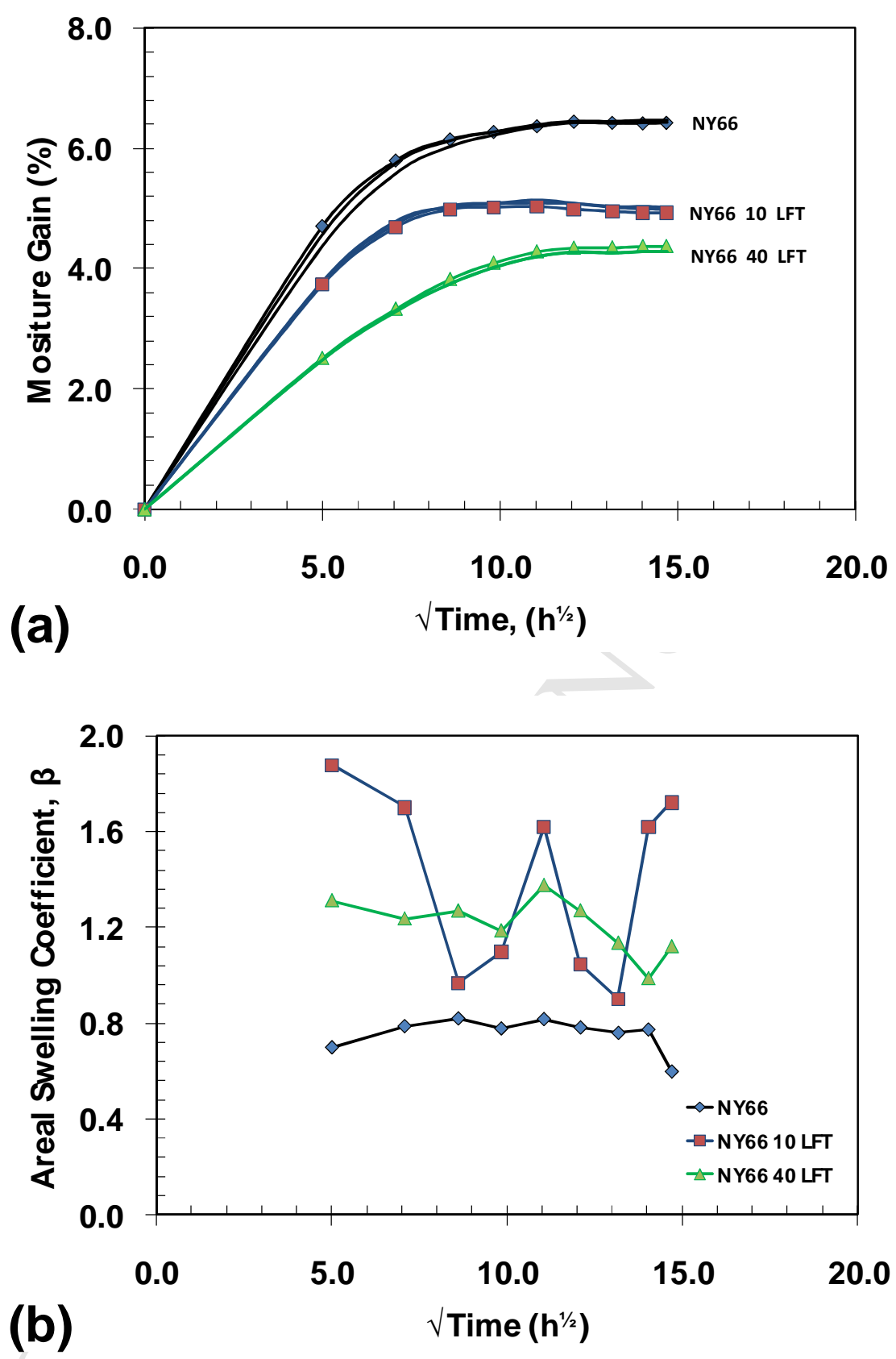

Fig. 15. Change in a) weight gain with progressing water immersion time and b) areal swelling coefficient. 


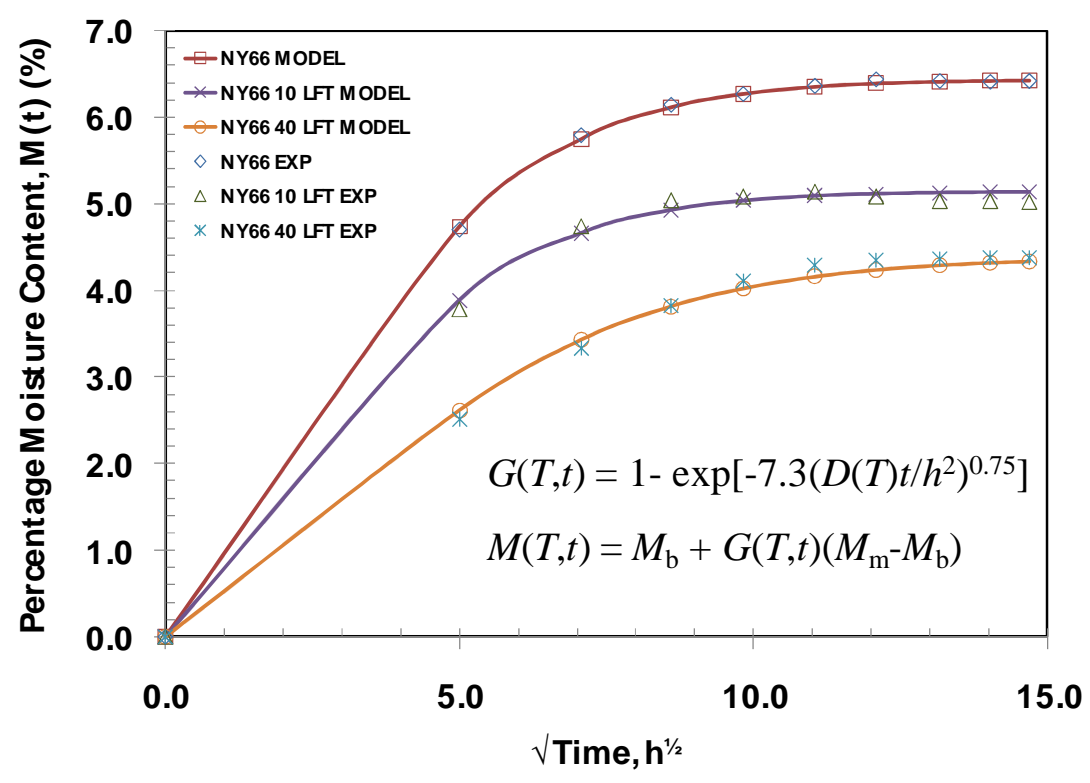

Fig. 16. A comparison of Fickian moisture absorption model to the experimental data that shows a close fit. 


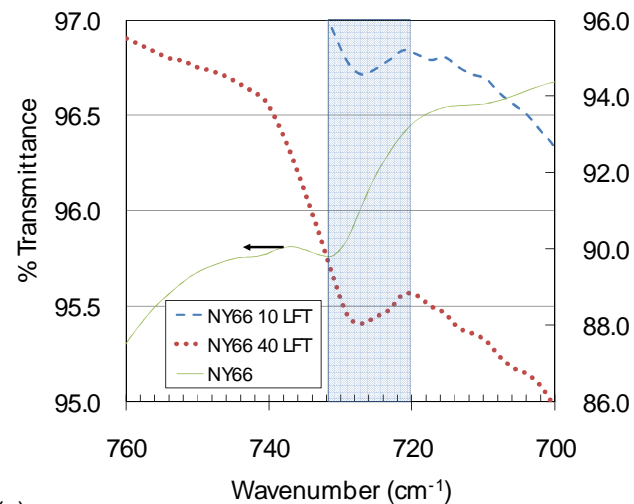

(a)

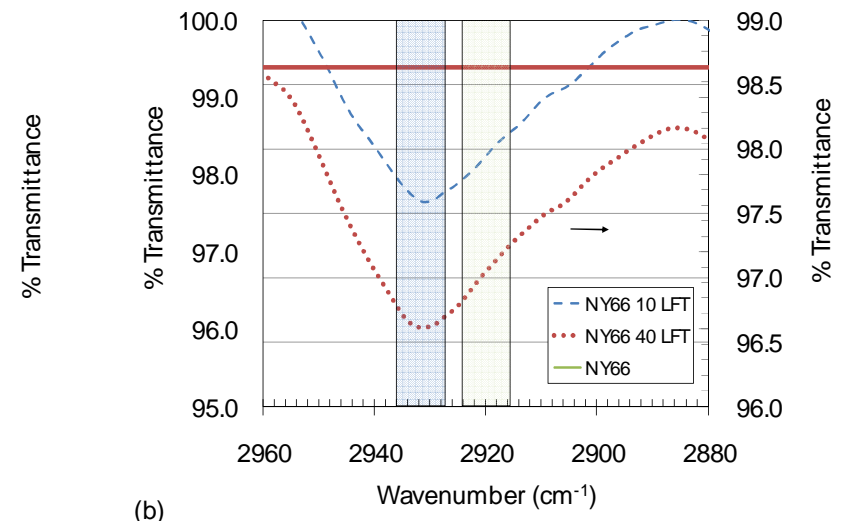

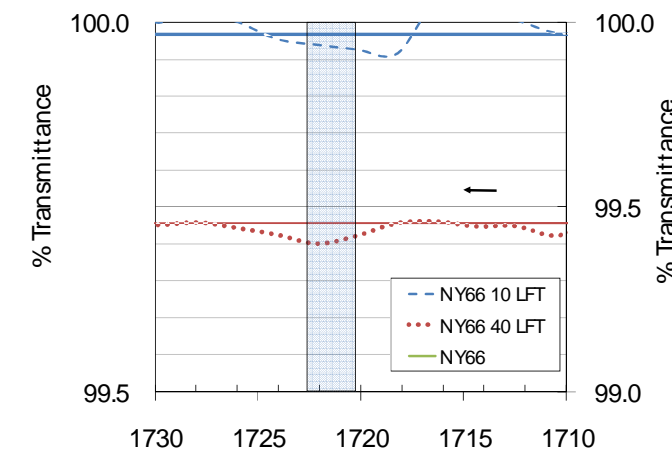

(c)

Wavenumber $\left(\mathrm{cm}^{-1}\right)$

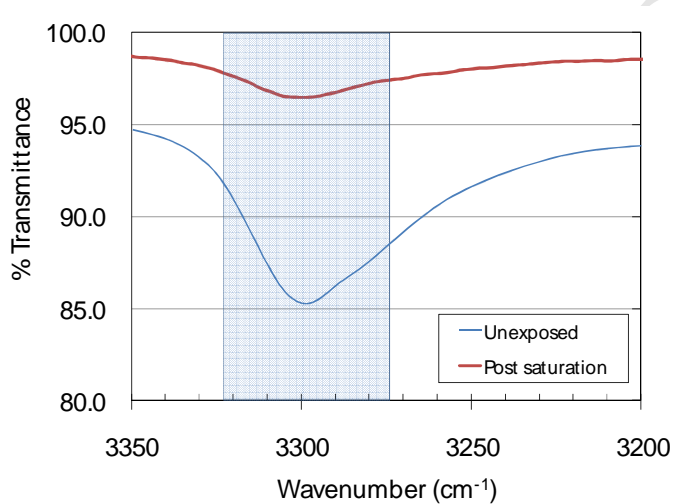

(e)

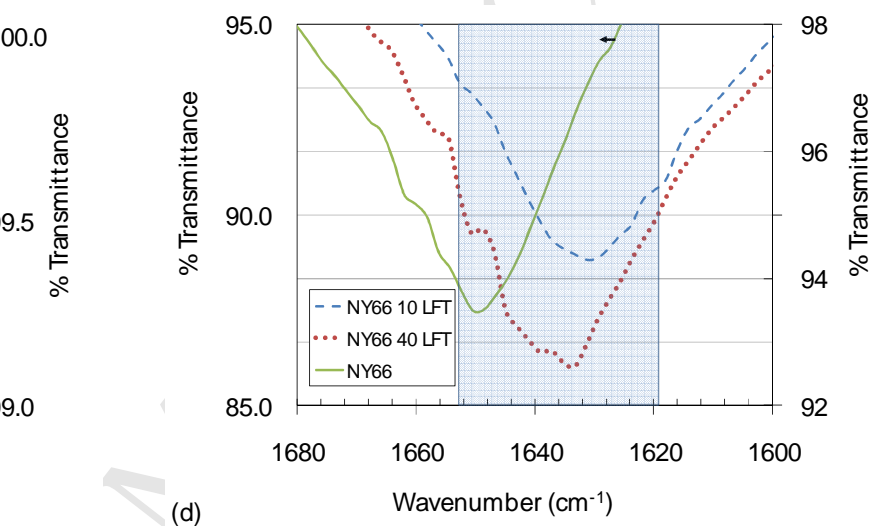

(d)

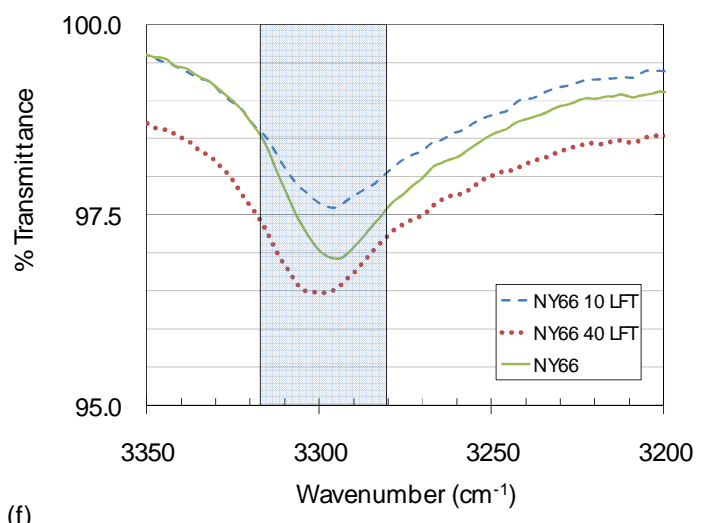

Fig. 17. FTIR spectra of water-saturated NY66, NY66 10 LFT, and NY66 40 LFT. Fingerprint region peaks, a) $-\mathrm{CH}_{2}$ rocking, $730 \mathrm{~cm}^{-1}$, b) $-\mathrm{CH}_{2}$ asymmetric stretching, $2930 \mathrm{~cm}^{-1}$. Functional group peaks, c) Carbonyl, $-\mathrm{C}=\mathrm{O}, 1720 \mathrm{~cm}^{-1}$, d) Amide-I, $-\mathrm{NH}_{2}, 1630 \mathrm{~cm}^{-1}$. Hydroxyl $(-\mathrm{OH})$ band for e) saturated and unexposed NY66 40 LFT and f) Hydroxyl group for the three materials, $3300 \mathrm{~cm}^{-1}$. 

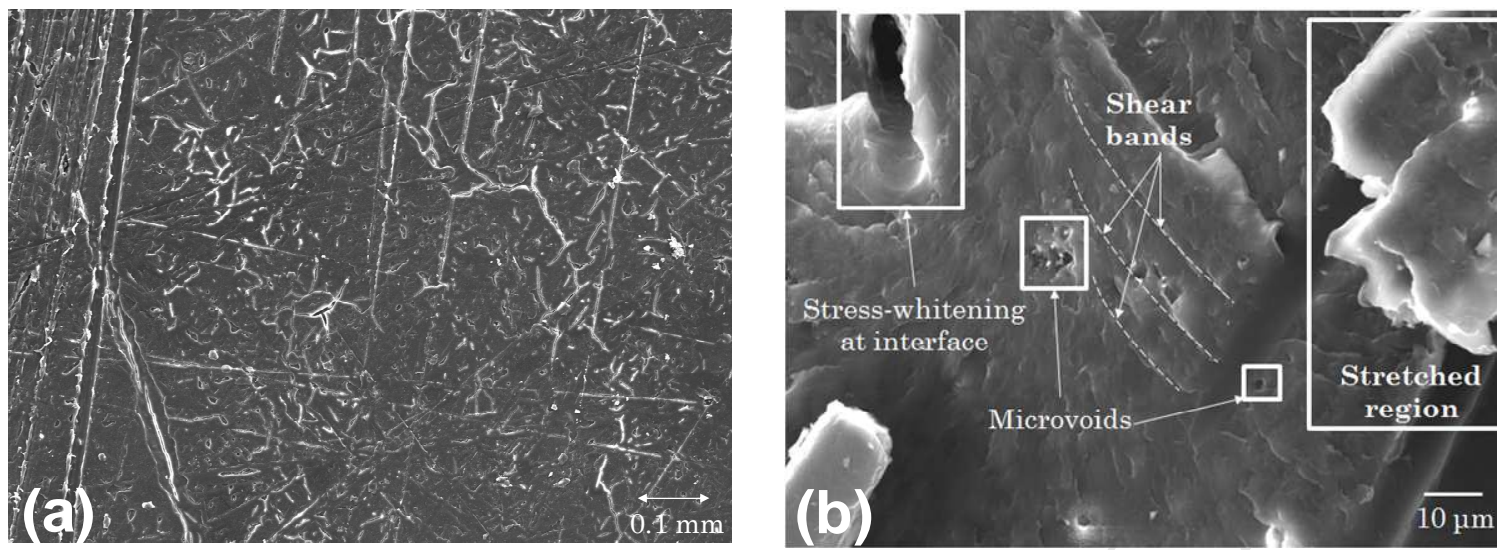

Fig. 18. Matrix crazing observed on surface of specimens immersed in boiling water. 

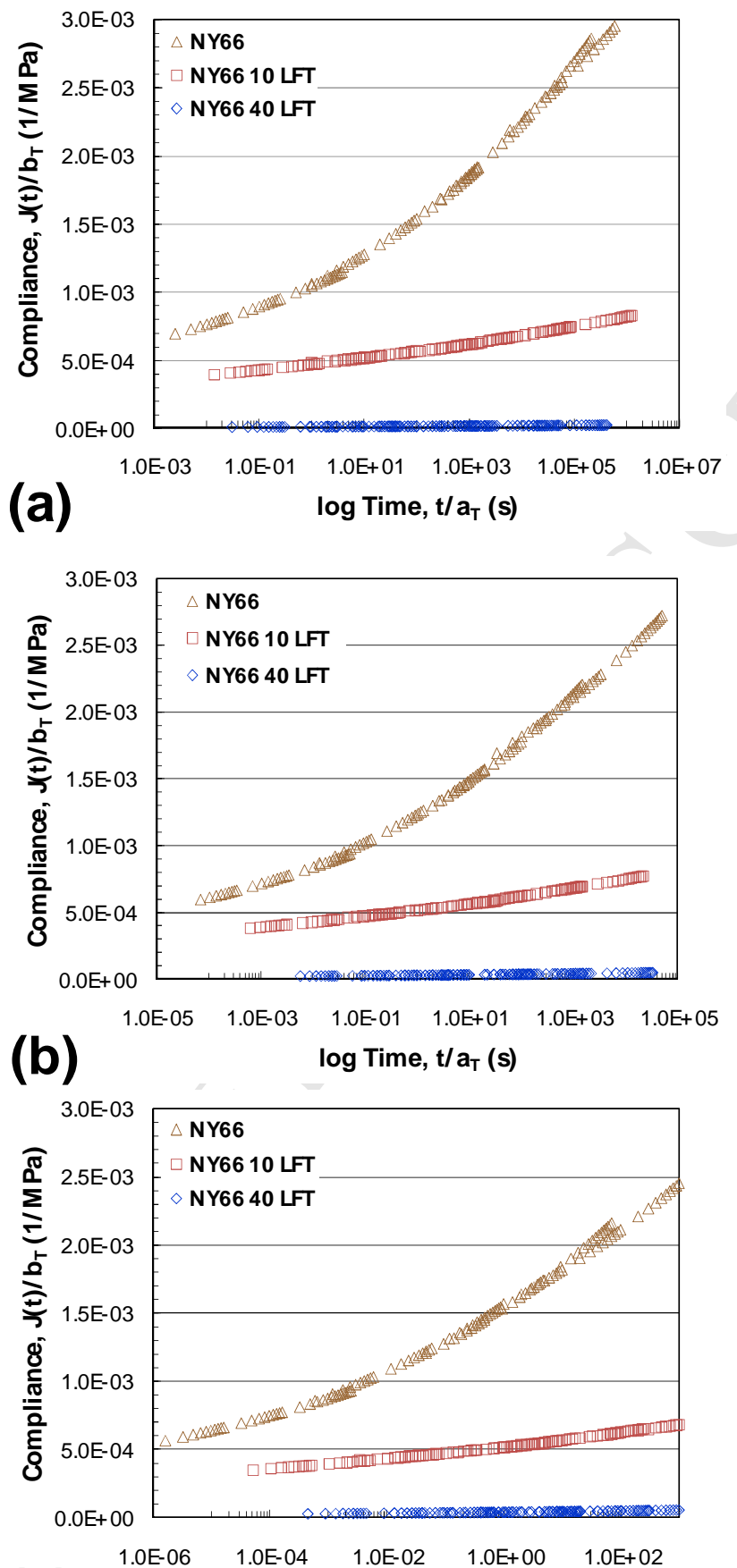

(c) $\log$ Time, $\mathbf{t} / \mathbf{a}_{\mathrm{T}}(\mathbf{s})$

Fig. 19. Time-temperature-stress superposition curves for post-saturation NY66, NY66 10 LFT, and NY66 40 LFT at a) $50{ }^{\circ} \mathrm{C}$, b) $70{ }^{\circ} \mathrm{C}$, and c) $90{ }^{\circ} \mathrm{C}$. 